\title{
Organic photolysis reactions in tropospheric aerosols: effect on secondary organic aerosol formation and lifetime
}

\author{
A. Hodzic ${ }^{1}$, S. Madronich ${ }^{1}$, P. S. Kasibhatla ${ }^{2}$, G. Tyndall ${ }^{1}$, B. Aumont ${ }^{3}$, J. L. Jimenez ${ }^{4}$, J. Lee-Taylor ${ }^{1}$, and J. Orlando ${ }^{1}$ \\ ${ }^{1}$ National Center for Atmospheric Research, Boulder, CO, USA \\ ${ }^{2}$ Nicholas School of the Environment, Duke University, Durham, NC, USA \\ ${ }^{3}$ LISA UMR CNRS 7583, Université Paris Est Créteil et Université Paris Diderot, Paris, France \\ ${ }^{4}$ University of Colorado, Boulder, CO, USA
}

Correspondence to: A. Hodzic (alma@ucar.edu)

Received: 18 February 2015 - Published in Atmos. Chem. Phys. Discuss.: 17 March 2015

Revised: 6 July 2015 - Accepted: 25 July 2015 - Published: 20 August 2015

\begin{abstract}
This study presents the first modeling estimates of the potential effect of gas- and particle-phase organic photolysis reactions on the formation and lifetime of secondary organic aerosols (SOAs). Typically only photolysis of smaller organic molecules (e.g., formaldehyde) for which explicit data exist is included in chemistry-climate models. Here, we specifically examine the photolysis of larger molecules that actively partition between the gas and particle phases. The chemical mechanism generator GECKO-A is used to explicitly model SOA formation from $\alpha$-pinene, toluene, and $\mathrm{C}_{12}$ and $\mathrm{C}_{16} n$-alkane reactions with $\mathrm{OH}$ at low and high $\mathrm{NO}_{x}$. Simulations are conducted for typical midlatitude conditions and a solar zenith angle of $45^{\circ}$ (permanent daylight). The results show that after 4 days of chemical aging under those conditions (equivalent to 8 days in the summer mid-latitudes), gas-phase photolysis leads to a moderate decrease in SOA yields, i.e., $\sim 15 \%\left(\right.$ low $\mathrm{NO}_{x}$ ) to $\sim 45 \%\left(\right.$ high $\mathrm{NO}_{x}$ ) for $\alpha$-pinene, $\sim 15 \%$ for toluene, $\sim 25 \%$ for $\mathrm{C}_{12} n$-alkane, and $\sim 10 \%$ for $\mathrm{C}_{16} n$-alkane. The small effect of gas-phase photolysis on low-volatility $n$-alkanes such as $\mathrm{C}_{16} n$-alkane is due to the rapid partitioning of early-generation products to the particle phase, where they are protected from gas-phase photolysis. Minor changes are found in the volatility distribution of organic products and in oxygen to carbon ratios. The decrease in SOA mass is increasingly more important after a day of chemical processing, suggesting that most laboratory experiments are likely too short to quantify the effect of gas-phase photolysis on SOA yields. Our results also suggest that many molecules containing chromophores are preferentially partitioned into
\end{abstract}

the particle phase before they can be photolyzed in the gas phase. Given the growing experimental evidence that these molecules can undergo in-particle photolysis, we performed sensitivity simulations using an empirically estimated SOA photolysis rate of $J_{\mathrm{SOA}}=4 \times 10^{-4} J_{\mathrm{NO}_{2}}$. Modeling results indicate that this photolytic loss rate would decrease SOA mass by $40-60 \%$ for most species after 10 days of equivalent atmospheric aging at mid-latitudes in the summer. It should be noted that in our simulations we do not consider in-particle or aqueous-phase reactions which could modify the chemical composition of the particle and thus the quantity of photolabile species. The atmospheric implications of our results are significant for both the SOA global distribution and lifetime. GEOS-Chem global model results suggest that particle-phase photolytic reactions could be an important loss process for SOA in the atmosphere, removing aerosols from the troposphere on timescales of less than 7 days that are comparable to wet deposition.

\section{Introduction}

Secondary organic aerosols (SOAs) are ubiquitous atmospheric constituents formed by photochemical oxidation of anthropogenic and biogenic hydrocarbons that can lead to adverse health effects (Fann et al., 2012) and radiative forcing of climate (Boucher et al., 2013). Their atmospheric burden and lifetime are highly uncertain due to our limited understanding of processes controlling their formation, aging and removal in the atmosphere. SOA yields and the volatil- 
ity distribution of intermediate oxidation products greatly depend on the competitive chemistry of peroxy radicals $\left(\mathrm{RO}_{2}\right)$ formed from oxidation of parent hydrocarbons, which can react with nitrogen oxides (NO), hydroperoxy radicals $\left(\mathrm{HO}_{2}\right)$, or other $\mathrm{RO}_{2}$ (Ziemann and Atkinson, 2012). The resulting oxygenated molecules contain carbonyl, peroxide or nitrate chromophores, and are potentially sensitive to photolysis during their lifetime in the atmosphere (Finlayson-Pitts and Pitts, 2000). Photolysis can occur in the gas phase and in the condensed phase as particles containing photolabile compounds efficiently absorb light at actinic wavelengths (e.g., Lambe et al., 2013; Wong et al., 2014). Unlike OH reactions that mainly lead to addition of more functional groups, photolysis mainly fragments molecules into smaller and more volatile compounds, thus significantly modifying SOA composition and properties during atmospheric aging.

Evidence that photolysis modulates SOA formation and lifetime in the atmosphere is supported by a growing number of laboratory experiments, which showed that exposure to UV lights can suppress SOA formation or even cause substantial loss of biogenic SOA. Presto et al. (2005) observed a $20-40 \%$ decrease in aerosol yields during $\alpha$ pinene ozonolysis experiments conducted under UV lights. Zhang et al. (2006) found similar sensitivity to UV exposure for $d$-limonene ozonolysis SOA, with a mass yield decrease of $60 \%$ for compounds with saturation concentration of $1 \mu \mathrm{g} \mathrm{m}^{-3}$. In both cases, the SOA decrease was attributed to the photolysis of gas-phase intermediates during the active growth phase and changes in their volatility distribution. Specific SOA aging experiments were also performed to isolate the effect of photolysis from other processes (e.g., Tritscher et al., 2011; Salo et al., 2011; Henry and Donahue, 2012; Donahue et al., 2012). In those experiments, SOA was first formed from $\alpha$-pinene ozonolysis in the dark, and then the products were irradiated (with UV lamps or solar lights), which allowed separation of the aging by $\mathrm{OH}$-radical oxidation and photolysis from the initial condensation of primary products. Henry and Donahue (2012) reported a strong photolytic loss of $6 \times 10^{-5} \mathrm{~s}^{-1}$ of the formed SOA mass upon UV $360 \mathrm{~nm}$ black-light exposure with lower $\mathrm{OH}$ levels $\left(\sim 10^{6}\right.$ molecules $\left.\mathrm{cm}^{-3}\right)$ via $\mathrm{H}_{2} \mathrm{O}_{2}$ photolysis. In additional experiments reported by Donahue et al. (2012), where OH was formed via HONO photolysis, an initial increase in SOA concentrations was first observed, followed by their strong decrease as $\mathrm{OH}$ concentrations dropped from $10^{7}$ to $10^{6}$ molecules $\mathrm{cm}^{-3}$. The authors attributed this SOA loss to photolysis in the gas phase followed by particle-to-gas re-equilibration, under the assumption that particle-phase quantum yields of photodissociation are small due to quenching and cage effects from neighboring molecules. However, recent studies that were able to decouple gas-phase and condensed-phase processes seem to suggest a rapid photolytic loss of SOA in the condensed phase. Epstein et al. (2014) irradiated $\alpha$-pinene ozonolysis SOA denuded from gas-phase oxidants and organic vapors, and con- cluded that condensed-phase photolysis was responsible for a significant decrease in SOA mass caused by the photochemical loss of particle-bound peroxide species (a $50 \%$ loss over 1 equivalent week in the atmosphere). Wong et al. (2014) also reported a substantial photolytic loss of $\alpha$-pinene SOA mass (generated by re-atomization after sampling into filters) under UVB lights with loss rates of $7.9 \times 10^{-5} \mathrm{~s}^{-1}$ under dry conditions and a 2 -fold faster loss $\left(1.6 \times 10^{-4} \mathrm{~s}^{-1}\right)$ under higher relative humidities.

During photochemical aging in the atmosphere, SOA can be both generated by oxidative functionalization with $\mathrm{OH}$ and destroyed by photolysis. As these processes are occurring simultaneously and during the entire organic aerosol (OA) life cycle in the atmosphere (typically a week), it is currently challenging to quantify separately the effect of photolysis on SOA yields and aging from laboratory experiments, and to describe their effect in the models. To our knowledge, photolysis of oxygenated organic molecules in the gas or condensed phase is ignored in most current chemistryclimate models, which could result in substantial errors in SOA predictions. In addition, the experimental quantification of SOA photolytic loss could be significantly biased due to SOA evaporation caused by heating inside the chamber upon UV light exposure (Denjean et al., 2015).

The objective of the present study is to examine the effect of both gas- and condensed-phase photolysis on SOA formation and lifetime using process and global modeling. First, we study the multi-day growth of SOA from four typical precursors ( $\alpha$-pinene, toluene, and semi-volatile and intermediate volatility $n$-alkanes) under idealized conditions (constant fixed daylight, temperature, $\mathrm{OH}, \mathrm{NO}_{x}, \mathrm{O}_{3}$, and preexisting $\mathrm{OA}$ ) to assess the maximum potential impact of photolysis on SOA formation. The mechanism generator GECKO-A is used to create explicit oxidation schemes for these precursors, which are then run within a box model to assess the effect of photolysis on SOA yields under a range of conditions. The effect of gas-phase photolysis is explicitly quantified in the box model, whereas the potential role of in-particle photolysis is empirically estimated and discussed based on sensitivity simulations. We then include a simplified parameterization of photolysis reactions within a global chemistry model to estimate the potential effect of photolysis on ambient SOA under realistic conditions involving spatial and temporal variability in SOA precursor emissions and chemistry, and in the presence of other competing SOA loss processes.

\section{Modeling framework}

The mechanism self-generator GECKO-A (Generator of Explicit Chemistry and Kinetics of Organics in the Atmosphere) was used in this study to create the detailed gas-phase oxidation mechanisms for individual SOA precursors including $\alpha$-pinene, toluene, and $\mathrm{C}_{12}$ and $\mathrm{C}_{16} n$-alkanes. The chemical mechanisms are created using a prescribed set of rules 
determining reaction pathways and rate coefficients, based on laboratory kinetic data, and structure-activity relationships as described by Aumont et al. (2005). The protocol currently implemented in GECKO-A allows the generation of chemical mechanisms for aliphatic species only. For aromatic species (i.e, toluene in this study), the mechanism is taken from the Master Chemical Mechanism (MCM) (Jenkin et al., 2003) up to the formation of ring-opening products, where mechanism generation by GECKO-A is next used. Rate coefficients for reaction of $\mathrm{OH}$ with organics are based on structure-reactivity rules of Kwok and Atkinson (1995) and subsequent updates. In this study, we have updated the rate constants for $\mathrm{H}$-atom abstraction from carbon atoms containing a hydroperoxide functionality (e.g., $\mathrm{RC}-\mathrm{H}(\mathrm{OOH}) \mathrm{R})$. Kinetic data for $\mathrm{OH} /$ hydroperoxide reactions are sparse in the literature, and previous versions of GECKO-A assumed an activation factor (i.e., an enhancement of the rate constant due to the presence of the functional group) of 14 on the basis of data for the $\mathrm{OH} / \mathrm{CH}_{3} \mathrm{OOH}$ reaction. That is, the presence of the $-\mathrm{OOH}$ group was assumed to increase the reactivity of the adjacent $\mathrm{C}-\mathrm{H}$ bond(s) by this factor. We have changed this factor to 3.5, similar to that for $-\mathrm{OH}$ (R. Atkinson, personal communication, 2014), and discuss its effect on our results in Sect. 3.1. The choice of a lower activation factor is supported by measurements of gas-phase dodecyl hydroperoxides in the work of Yee et al. (2012), who found that the loss of these peroxides was much too fast when using the MCM value based on a large value of $F(-\mathrm{OOH})$. For the gas-particle partitioning, instantaneous equilibrium is assumed, and the Nannoolal et al. (2008) approach is used to estimate the saturation vapor pressure for non-radical species. The fraction that is partitioned to the particle phase can be determined as $F_{\text {aerosol }, i}=\left(\frac{C_{\mathrm{OA}}}{C_{\mathrm{OA}}+C_{i}^{*}}\right)$, where $\mathrm{C}_{\mathrm{OA}}$ is the aerosol mass concentration $\left(\mu \mathrm{g} \mathrm{m}^{-3}\right)$, and is an effective saturation mass concentration $\left(\mu \mathrm{g} \mathrm{m}^{-3}\right)$. The gas-particle equilibrium and the composition of SOA are constantly modified as the gas-phase oxidation progresses during the atmospheric aging. Condensed-phase reactions are not considered, nor are potential diffusion limitations to SOA partitioning. Gas-phase photolytic reactions are included for molecules containing carbonyl, hydroperoxide or nitrate chromophores. For species containing several functional groups, each chromophore is treated independently, except for conjugated carbonyls. The photolysis of nitroaromatic compounds is not included. To determine the associated photolysis rates, each molecular structure predicted by GECKO-A is assigned a reference compound with its associated cross sections and quantum yields as described by Aumont et al. (2005; see Table 4). Table S1 in the Supplement summarizes the photolysis rates for chromophores and molecular structures that are considered in GECKO-A. Particle-phase photolysis is not explicitly calculated in the default model, and sensitivity simulations will be performed in this study to quantify its effects as discussed in Sect. 3.2.
In this study simulations are performed in a box model with the prescribed conditions representative of ambient air as in the study by Hodzic et al. (2014) to quantify the effect of photolysis on SOA formation and yields. In these runs, temperature is set to $298 \mathrm{~K}$, photolysis frequencies are calculated for mid-latitudes at a solar zenith angle of $45^{\circ}$ $\left(J_{\mathrm{NO}_{2}}=8.1 \times 10^{-3} \mathrm{~s}^{-1}\right.$, which corresponds to constant daylight), $\mathrm{NO}_{x}$ levels are held at $0.01 \mathrm{ppb}$ for low and $10 \mathrm{ppb}$ for high- $\mathrm{NO}_{x}$ conditions, ozone is set at $40 \mathrm{ppb}$, and $\mathrm{OH}$ is kept constant at $2 \times 10^{6}$ molecules $\mathrm{cm}^{-3}$. The preexisting OA concentration is $10 \mu \mathrm{g} \mathrm{m}^{-3}$, typical of moderately polluted conditions. Sensitivity simulations with higher $\mathrm{OH}$ values $\left(8 \times 10^{6}\right.$ molecules $\left.\mathrm{cm}^{-3}\right)$ or lower preexisting OA $\left(1 \mu \mathrm{g} \mathrm{m}^{-3}\right)$ are also performed. The initial hydrocarbon mixing ratio is fixed to an arbitrary low value of $1 \mathrm{ppt}$, so that the amount of aerosol produced from the given precursor is negligible compared to preexisting OA prescribed in the study and will not impact the gas-particle partitioning, nor the overall photochemical reactivity. Under these conditions, SOA yields are independent of the amount of initial precursor as discussed by Hodzic et al. (2014). SOA yields and volatility distribution of intermediate products depend to a large extent on the relative rates of $\mathrm{RO}_{2}+\mathrm{HO}_{2}$ and $\mathrm{RO}_{2}+\mathrm{RO}_{2}$ (minor) vs. $\mathrm{RO}_{2}+\mathrm{NO}$ reactions. We calculated that $8 \%$ of $\mathrm{RO}_{2}$ reactions proceed with $\mathrm{NO}$ under "low- $\mathrm{NO}_{x}$ " conditions vs. $99.9 \%$ under "high- $\mathrm{NO}_{x}$ " conditions considered in this study.

We define the photolysis age in $J_{\mathrm{NO}_{2}}$ equivalent days (Table 1) as the $J_{\mathrm{NO}_{2}}$ exposure of the simulated SOA during our simulations normalized to a 1-day average summer (or winter) $J_{\mathrm{NO}_{2}}$ exposure: photolysis age $=\frac{\left(J_{\mathrm{NO}_{2}} \times \text { time }\right)}{J_{\mathrm{NO}_{2} \_ \text {average }}}$, where "time" is the duration of the simulation in days. Photolysis age values are reported in Table 1 for our experiments. Typically, our 1-week simulations performed under constant light at mid-latitudes and a solar zenith angle of $45^{\circ}$ $\left(J_{\mathrm{NO}_{2}}=8.1 \times 10^{-3} \mathrm{~s}^{-1}\right)$ are equivalent to about 2 equivalent weeks of exposure in the atmosphere at mid-latitudes during summer, or about 38 equivalent days during winter.

\section{Results and discussion}

\subsection{Importance of gas-phase photolysis of organics}

To investigate the role of gas-phase photolysis on SOA formation and yields, we compared experiments with photolysis on and off for four typical SOA precursors including $\alpha$-pinene, toluene, and $\mathrm{C}_{12}$ and $\mathrm{C}_{16} n$-alkanes (Table 2). In the "photolysis-off" experiment, photolysis of all organic species (except for formaldehyde and methyl hydroperoxide) is turned off, whereas all inorganic compounds (i.e., $\mathrm{O}_{3}, \mathrm{NO}_{2}, \mathrm{NO}_{3}, \mathrm{H}_{2} \mathrm{O}_{2}, \mathrm{HONO}, \mathrm{HNO}_{3}, \mathrm{HNO}_{4}$ ) still undergo photolysis. Figure 1 shows the results for two different levels of $\mathrm{NO}_{x}(0.01$ and $10 \mathrm{ppb}), \mathrm{OH}\left(2 \times 10^{6}\right.$ and $8 \times 10^{6}$ molecules $\mathrm{cm}^{-3}$ ) and background OA (1 and 
Table 1. Photolysis rate coefficients and photolytic lifetimes for typical atmospheric conditions and for our simulations. Typical ozone overhead values are used at different locations based on Total Ozone Mapping Spectrometer data (http://disc.sci.gsfc.nasa.gov/acdisc/TOMS).

\begin{tabular}{|c|c|c|c|c|c|c|}
\hline \multicolumn{4}{|l|}{ Typical conditions } & \multirow{2}{*}{$\begin{array}{r}\text { Average } \\
J_{\mathrm{NO}_{2}\left(\mathrm{~s}^{-1}\right)} \\
4.1 \times 10^{-3}\end{array}$} & \multirow{2}{*}{$\begin{array}{r}\text { Average } \\
J_{\mathrm{O} 1 \mathrm{D}}\left(\mathrm{s}^{-1}\right) \\
1.0 \times 10^{-5}\end{array}$} & \multirow{2}{*}{$\begin{array}{r}\text { Average } \\
J_{\mathrm{NO}_{3}->\mathrm{NO}_{2}+\mathrm{O}\left(\mathrm{s}^{-1}\right)} \\
9.1 \times 10^{-2}\end{array}$} \\
\hline Boulder, $\mathrm{CO}$, summer solstice & \multicolumn{3}{|c|}{$\begin{array}{l}40^{\circ} \mathrm{N} \text {, sea level, } 21 \text { June, } \\
\mathrm{O}_{3 \text { col. }}=310 \mathrm{DU}, 10 \% \text { ground albedo } \\
\text { no aerosols, no clouds }\end{array}$} & & & \\
\hline $\begin{array}{l}\text { Boulder, } \mathrm{CO}, \\
\text { winter } \\
\text { solstice }\end{array}$ & \multicolumn{3}{|c|}{$\begin{array}{l}40^{\circ} \mathrm{N} \text {, sea level, } 21 \mathrm{Dec} \\
\mathrm{O}_{3 \text { col. }}=330 \mathrm{DU}, 10 \% \text { ground albedo } \\
\text { no aerosols, no clouds }\end{array}$} & $1.5 \times 10^{-3}$ & $1.2 \times 10^{-6}$ & $4.6 \times 10^{-2}$ \\
\hline $\begin{array}{l}\text { Equator, } \\
21 \text { June }\end{array}$ & \multirow{2}{*}{\multicolumn{3}{|c|}{$\begin{array}{l}\text { Sea level, } \mathrm{O}_{3 \text { col. }}=260 \mathrm{DU}, 5 \% \text { ground } \\
\text { albedo, no aerosols, no clouds } \\
\text { Sea level, } \mathrm{O}_{3 \text { col. }}=258 \mathrm{DU}, 5 \% \text { ground } \\
\text { albedo, no aerosols, no clouds }\end{array}$}} & $3.3 \times 10^{-3}$ & $1.0 \times 10^{-5}$ & $7.3 \times 10^{-2}$ \\
\hline $\begin{array}{l}\text { Equator, } \\
21 \text { March }\end{array}$ & & & & $3.6 \times 10^{-3}$ & $1.3 \times 10^{-5}$ & $7.8 \times 10^{-2}$ \\
\hline $\begin{array}{l}\text { Hyytiälä, } \\
\text { summer solstice }\end{array}$ & \multirow{2}{*}{\multicolumn{3}{|c|}{$\begin{array}{l}61^{\circ} \mathrm{N}, \text { June } 21, \mathrm{O}_{3 \mathrm{col}}=355 \mathrm{DU}, 5 \% \text { ground } \\
\text { albedo, no aerosols, no clouds } \\
61^{\circ} \mathrm{N}, 21 \mathrm{Dec}, \mathrm{O}_{3 \mathrm{col} .}=355 \mathrm{DU}, 90 \% \text { ground } \\
\text { albedo, no aerosols, no clouds }\end{array}$}} & $4.3 \times 10^{-3}$ & $6.2 \times 10^{-6}$ & $1.0 \times 10^{-1}$ \\
\hline $\begin{array}{l}\text { Hyytiälä, } \\
\text { winter solstice }\end{array}$ & & & & $2.6 \times 10^{-4}$ & $5.8 \times 10^{-8}$ & $1.0 \times 10^{-2}$ \\
\hline \multirow[t]{2}{*}{ Model simulation } & & $\begin{array}{r}\text { Average } \\
J_{\mathrm{NO}_{2}}\left(\mathrm{~s}^{-1}\right)\end{array}$ & $\begin{array}{r}\text { Average } \\
J_{\mathrm{O} 1 \mathrm{D}}\left(\mathrm{s}^{-1}\right)\end{array}$ & $\begin{array}{r}\text { Average } \\
J_{\mathrm{NO}_{3}->\mathrm{NO}_{2}+\mathrm{O}\left(\mathrm{s}^{-1}\right)}\end{array}$ & \multicolumn{2}{|c|}{$\begin{array}{c}\text { Photolysis age in } J_{\mathrm{NO}_{2}} \\
\text { equivalent days }\end{array}$} \\
\hline & & & & & $\begin{array}{r}\text { Boulder, } \mathrm{CO} \text {, } \\
\text { summer solstice }\end{array}$ & $\begin{array}{r}\text { Boulder, CO, } \\
\text { winter solstice }\end{array}$ \\
\hline $\begin{array}{l}\text { GECKO-A } 1 \text { week } \\
\text { simulations (Table 2) }\end{array}$ & $\begin{array}{l}40^{\circ} \mathrm{N}, 45^{\circ} \text { solar } \\
\text { zenith angle, } 7 \text { days }\end{array}$ & $8.1 \times 10^{-3}$ & $2.1 \times 10^{-5}$ & $1.8 \times 10^{-1}$ & 14 eq. days & 38 eq. days \\
\hline $\begin{array}{l}\text { GECKO-A } \alpha \text {-pinene } \\
\text { ozonolysis SOA (Fig. 6) }\end{array}$ & $\begin{array}{l}\text { Black lights, } \\
5 \mathrm{~h}\end{array}$ & $3.0 \times 10^{-3}$ & $1.2 \times 10^{-5}$ & $2.1 \times 10^{-3}$ & $\begin{array}{r}0.15 \text { eq. days } \\
\text { (3.7 eq. hours) }\end{array}$ & $\begin{array}{r}0.42 \text { eq. days } \\
(10 \text { eq. hours) }\end{array}$ \\
\hline $\begin{array}{l}\text { Henry and } \\
\text { Donahue (2012) }\end{array}$ & $\begin{array}{l}\text { Black lights, } \\
5 \mathrm{~h}\end{array}$ & $3.0 \times 10^{-3}$ & - & - & $\begin{array}{r}0.15 \text { eq. days } \\
\text { (3.7 eq. hours) }\end{array}$ & $\begin{array}{l}0.42 \text { eq. days } \\
\text { (10 eq. hours) }\end{array}$ \\
\hline
\end{tabular}

$10 \mu \mathrm{g} \mathrm{m}^{-3}$ ). Base case simulations (BASE) with and without photolysis of organics are shown in black. The results indicate that in a week of chemical aging with constant daylight or two weeks of equivalent atmospheric summertime exposure (representative of Boulder, $40^{\circ} \mathrm{N}$, with the solar zenith angle of $45^{\circ}$ ), the gas-phase photolysis leads to a 10 to $45 \%$ decrease in SOA concentrations depending on the precursor. Most of the decrease occurs in the first 4 days of the simulation (8 equivalent atmospheric days). For a given species, the sensitivity to gas-phase photolysis is comparable under lowand high- $\mathrm{NO}_{x}$ conditions, except for $\alpha$-pinene SOA, which seems to be more sensitive under high- $\mathrm{NO}_{x}$ conditions. Our results also suggest that, for most species, the resulting loss of SOA due to gas-phase photolysis is increasingly more important as the chemical processing time is increased during the first week atmospheric exposure (Fig. S1 in the Supplement).

The largest effect on yields (Table 3 ) is predicted for $\alpha$ pinene SOA, with a reduction of $16 \%$ under low $\mathrm{NO}_{x}$ and $47 \%$ under high $\mathrm{NO}_{x}$ during the entire experiment. The reduction is relatively small during the initial $10 \mathrm{~h}$, which is a typical duration of laboratory experiments, with a $2 \%$ decrease at low $\mathrm{NO}_{x}\left(10 \%\right.$ high $\left.\mathrm{NO}_{x}\right)$, and reaches $\sim 5 \%$ $(20 \%)$ after 1 day, or $12 \%(42 \%)$ after 1 week of equivalent atmospheric ageing. For toluene oxidation, the effect of photolysis is more limited, and does not exceed $15 \%$ for either low- or high- $\mathrm{NO}_{x}$ conditions. We note, however, that the effect could be underestimated as the photolysis of nitroaromatic compounds, which are strong absorbers, is currently not represented in GECKO-A. For products of $n$-alkanes, the relative decrease in SOA yields is $\sim 10 \%$ for $\mathrm{C}_{16} n$-alkanes and $\sim 25-30 \%$ for $\mathrm{C}_{12} n$-alkane. The sensitivity to gas-phase photolysis is more important for $\mathrm{C}_{12}$ than $\mathrm{C}_{16} n$-alkane, due to the fact that products of $\mathrm{C}_{16} n$-alkane are partitioned to the particle phase in a much greater fraction after one generation of chemistry, where they are protected from gas-phase photolysis, whereas it takes several generations to produce substantial SOA from shorter-chain $n$-alkanes (Aumont et al., 2012).

The efficiency of the gas-phase photolysis will depend on the residence time of organic vapors in the gas phase, which can be significantly modified by the chemical environment. For instance, an increase in the OA mass available for the gas-particle partitioning is expected to enhance the partitioning of organics to the condensed phase, where they will be protected from gas-phase photolysis. Similarly, a faster gasphase oxidation rate (higher $\mathrm{OH}$ ) is expected to lead to more rapid generation of the low-volatility organic species which can condense into the particle phase, thus making them less vulnerable to the gas-phase photolysis. Sensitivity simula- 
Table 2. Description of GECKO-A simulations.

\begin{tabular}{|c|c|c|c|c|}
\hline Exp & $\begin{array}{l}\text { Iments for SOA forme } \\
\text { Gas-phase photolysis } \\
\text { of organics }\end{array}$ & $\begin{array}{l}\text { from } \alpha \text {-pinene, tolue } \\
\text { Particle-phase } \\
\text { photolysis }\end{array}$ & $\begin{array}{l}\text { and } \mathrm{C}_{12} \text { and } \mathrm{C}_{1} \\
\mathrm{OH}(\mathrm{molecules} \\
\left.\mathrm{cm}^{-3}\right)\end{array}$ & $\begin{array}{l}n \text {-alkane } \\
\text { OA background } \\
\qquad\left(\mu \mathrm{g} \mathrm{m}^{-3}\right)\end{array}$ \\
\hline BASE & on/off & off & $2 \times 10^{6}$ & 10 \\
\hline SENS_OA & on/off & off & $2 \times 10^{6}$ & 1 \\
\hline SENS_OH & on/off & off & $8 \times 10^{6}$ & 1 \\
\hline$J_{\text {molecmax }} *$ & on & on as gas-phase $J$ & $2 \times 10^{6}$ & 10 \\
\hline$J_{\mathrm{mac}}$ & on & on as $0.04 \% J_{\mathrm{NO}_{2}}$ & $2 \times 10^{6}$ & 10 \\
\hline
\end{tabular}

* Radical species that are produced by photolysis inside the particle are assumed to be permanently lost to the gas phase.

Table 3. Predicted reduction in SOA yields due to gas-phase photolysis, and corresponding first-order loss rates and lifetimes. The results are from the GECKO-A BASE case simulation, and yields values are taken at the maximum of the SOA formation from each precursor. The loss rate coefficients were estimated by numerically fitting the first-order decay of SOA due to photolysis occurring over 1 week of processing under constant light $\left(\mathrm{NO}_{2}=8.1 \times 10^{-3} \mathrm{~s}^{-1}\right)$. Low $(0.01 \mathrm{ppb})$ and high $(10 \mathrm{ppb}) \mathrm{NO}_{x}$ simulations are shown.

\begin{tabular}{lrr|rr|rr}
\hline $\begin{array}{l}\text { Considered } \\
\text { system }\end{array}$ & \multicolumn{2}{c|}{$\begin{array}{c}\text { Reduction in SOA yields by } \\
\text { gas-phase photolysis }\end{array}$} & \multicolumn{2}{|c|}{$\begin{array}{c}\text { Estimated loss } \\
\text { rate }\left(\mathrm{s}^{-1}\right)\end{array}$} & $\begin{array}{c}\text { Estimated lifetime (days, under } \\
\text { simulation conditions*) }\end{array}$ \\
\hline & Low NO & High NO & Low NO & High NO & Low NO & ${\text { High } \mathrm{NO}_{x}}_{x}$ \\
\hline$\alpha$-pinene $+\mathrm{OH}$ & $-16 \%$ & $-47 \%$ & $4.6 \times 10^{-7}$ & $2.1 \times 10^{-6}$ & 25.0 & 5.4 \\
Toluene $+\mathrm{OH}$ & $-11 \%$ & $-13 \%$ & $5.6 \times 10^{-7}$ & $4.3 \times 10^{-7}$ & 20.8 & 27.0 \\
$\mathrm{C}_{12} \mathrm{H}_{26}+\mathrm{OH}$ & $-30 \%$ & $-28 \%$ & $1.2 \times 10^{-6}$ & $1.1 \times 10^{-6}$ & 9.3 & 10.4 \\
$\mathrm{C}_{16} \mathrm{H}_{34}+\mathrm{OH}$ & $-10 \%$ & $-13 \%$ & $3.6 \times 10^{-7}$ & $3.7 \times 10^{-7}$ & 30.0 & 31.0 \\
\hline
\end{tabular}

* To derive equivalent atmospheric loss rates (lifetimes) at mid-latitudes, values should be divided (multiplied) by a factor of 2 in summer and 5.4 in winter, which is the ratio between $J_{\mathrm{NO}_{2}}$ used in our experiment and the typical atmospheric values.

tions with 4-fold higher $\mathrm{OH}$ concentrations (SENS_OH) and 10-fold lower background OA (SENS_OA) are performed to evaluate these effects (Fig. 1). As expected, SOA formation occurs more rapidly when a 4-fold increase in $\mathrm{OH}$ is considered. The decrease by an order of magnitude in the amount of the preexisting OA (and thus reduced gas-particle partitioning) also affects the amount of SOA formed. A large $(\sim 75 \%)$ decrease in SOA production is observed for toluene because a significant fraction of the predicted oxidation products have effective saturation mass concentrations $\left(C^{*}\right)$ in the $1-10^{3} \mu \mathrm{g} \mathrm{m}^{-3}$ range (Fig. 4; see also Hodzic et al., 2014). The effect is more limited for SOA produced from other precursors (up to $30 \%$ ). For all precursor species, the sensitivity to photolytic reactions remains qualitatively similar (within 10\%) regardless of the $\mathrm{OH}$ and $\mathrm{OA}$ background values (Fig. S1 in the Supplement). As expected, a decrease in background OA concentrations leads in most cases to an enhancement of the SOA photolytic loss, whereas an increase in $\mathrm{OH}$ levels tends to result in a reduced SOA photolytic removal. We also note that the sensitivity to gas-phase photolysis is not significantly modified when diurnally variable photolysis rates are considered instead of fixed constant daylight conditions (see Fig. S3 in the Supplement).

Figure 2 shows the major functional groups in SOA molecules from various precursors. Fifteen families of func- tional groups are considered and they account for 54 to $65 \%$ of the total SOA mass for $\alpha$-pinene, 94 to $99 \%$ for toluene, and for 70 to $90 \%$ for $\mathrm{C}_{12}$ and $\mathrm{C}_{16} n$-alkanes. Positional isomers are lumped into the same family of compounds. Ketone $(\mathrm{K})$ and alcohol $(\mathrm{O})$ moieties are present in the majority of the molecules, while hydroperoxides $(\mathrm{H})$ are seen mainly at low $\mathrm{NO}_{x}$ and nitrates $(\mathrm{N})$ mainly at high $\mathrm{NO}_{x}$. Gas-phase photolysis leads to a decrease in most species, which seems to be particularly important for highly functionalized compounds containing multiple carbonyl and nitrate groups (e.g., HKKKK, HHKK, HHKKK, HKKK, NNKK, NNKO, where HHKK, for example, refers to a molecule that contains two hydroperoxide and two ketone groups). These species are formed by several generations of chemistry and are mainly found in the particle phase. Thus their decrease is more likely related to reductions in their precursor species due to photodegradation than to their direct loss by gas-phase photolysis. Some molecules containing alcohol groups (e.g., HHO, HKKO, HHKO) see an increase in their concentrations due to gas-phase photolysis (see also Fig. S2 in the Supplement). This increase can be explained by photolysis of hydroperoxides, which can lead to the formation of alkoxy radicals that can isomerize to form alcohols. Thus photolysis can contribute to SOA loss and to a lesser extent to its formation. Typically, photolysis of carbonyl compounds (ke- 

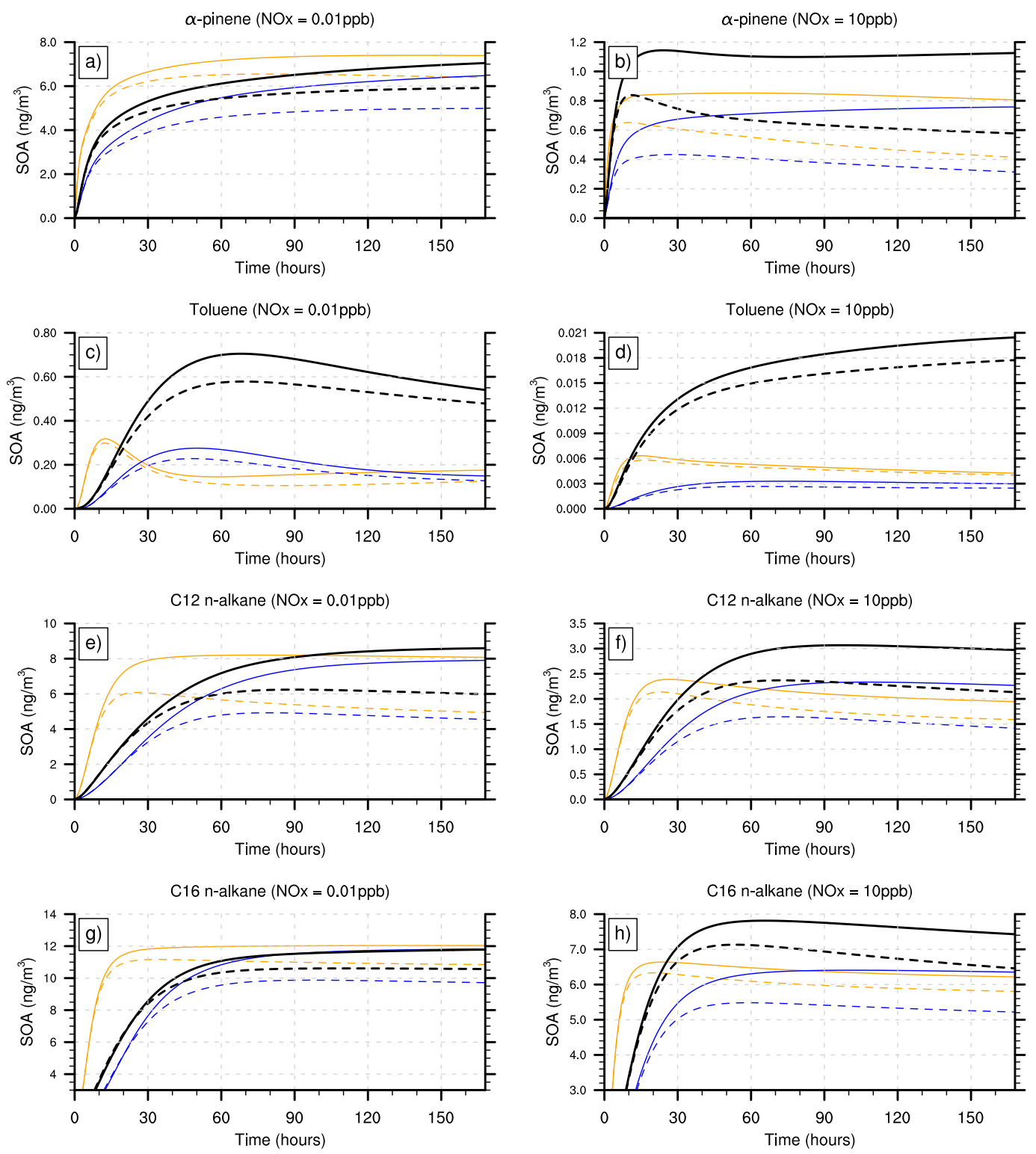

BASE SENS_OH SENS_OA

Figure 1. SOA formation from the oxidation by $\mathrm{OH}$ of $1 \mathrm{ppt}$ of $\alpha$-pinene, toluene, $\mathrm{C}_{12}$ and $\mathrm{C}_{16} n$-alkanes at low ( $\left.0.01 \mathrm{ppb}\right)$ and high (10 ppb) $\mathrm{NO}_{x}$ levels. Plots compare GECKO-A simulations with (dashed lines) and without (solid lines) gas-phase photolysis of organics at the solar zenith angle of $45^{\circ}$ (mid-latitudes) under constant daylight. To derive equivalent atmospheric summertime exposure of our experiment, the time axes should be multiplied by a factor of 2 (see Table 1). The reference simulation (BASE) is shown in black, and is compared to two sensitivity simulations testing for higher OH levels (SENS_OH in orange) and lower absorbing organic aerosol mass (SENS_OA in blue). See Table 2 for the description of various runs.

tone and aldehydes) tends to break the $\alpha$-carbon bond on either side of the $\mathrm{C}=\mathrm{O}$ group, leading to smaller more volatile fragments that are less likely to partition to the particle phase. On the other hand, photolysis of hydroperoxides and nitrates leads to elimination of $-\mathrm{OH}$ or $-\mathrm{NO}_{2}$, leading to alkoxy radicals, and potentially further functionalization of the carbon skeleton favoring formation of less volatile organic compounds that can partition more readily to the particle.
One of the highly uncertain factors that can influence the composition of SOA at low $\mathrm{NO}_{x}$ is the choice of the rate for abstracting the $\mathrm{H}$ atoms from the carbon atom that is adjacent to the hydroperoxide $(-\mathrm{OOH})$ group. As discussed in Sect. 2, in this paper we have used a lower activation factor of 3.5 for estimating the rate constant of that process, instead of the GECKO-A default value of 14 (Aumont et al., 2005). As shown in Fig. S4 in the Supplement this change does not 

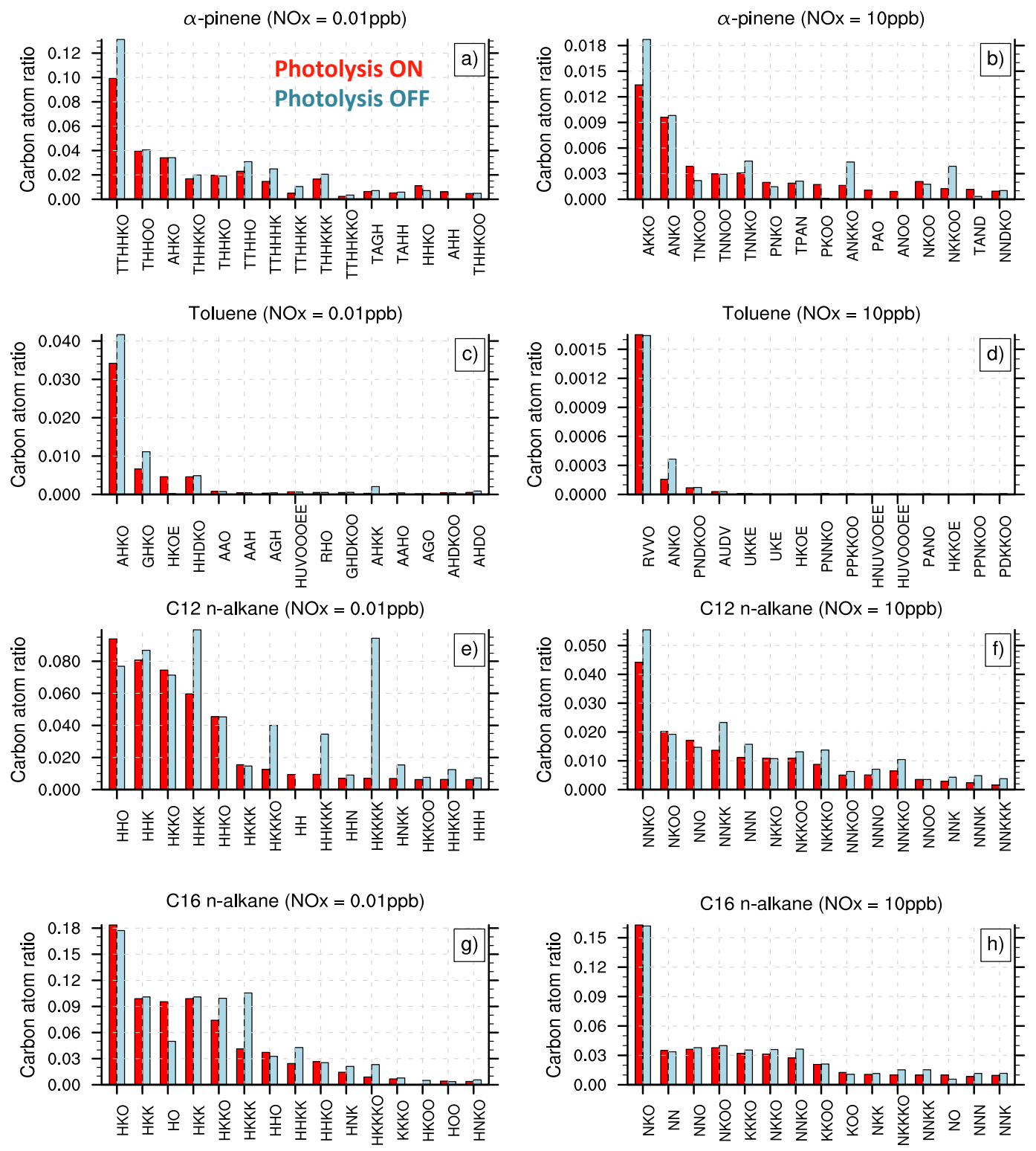

(A) Acid; (D) aldehyde; (H) hydroperoxide; (G) peracid; (K) ketone; (N) nitrate; (O) hydroxy;

(P) PAN; (R) aromatic ring; (T) non-aromatic ring; (U) unsaturated; $(\mathrm{V})=$ nitro

Figure 2. Particle-phase dominant functional groups in the top 15 SOA constituents shown at the maximum of the SOA yield. The BASE case simulations with (red bars) and without (blue bars) photolysis of organic compounds are compared. The carbon atom ratio indicates the ratio of the carbon atoms in the condensed phase to the initial carbon load included in the parent backbone. The sum of the shown particle-phase constituents is lower than 1 as the rest of the carbon mass is in the gas phase.

affect the SOA production when the gas-phase photolysis of organics is turned off $\left(\sim 8 \mu \mathrm{g} \mathrm{m}^{-3}\right.$ for $\mathrm{C}_{12} n$-alkane). However, the composition of SOA formed from $n$-alkanes is significantly modified, as is the effect of gas-phase photolysis on SOA yields $(\sim 2$-fold smaller when the value of 3.5 is considered). The main difference is found for HKKKK and HKKK molecules, which are much more abundant when the value of 14 is used. These molecules originate typically from the successive $\mathrm{OH}$ reaction, leading to hydroperoxide moi- eties under low- $\mathrm{NO}_{x}$ conditions and their subsequent fast oxidation to a ketone moiety due to a the large activation factor used. Reducing this factor to 3.5 forces the $\mathrm{OH}$ to react away from the $-\mathrm{OOH}$ group. When the carbon backbone is sparsely functionalized, this increases the rate of production of multifunctional species, in particular multifunctional peroxides (e.g., HHO and HHK). However, when the carbon backbone is highly functionalized, this leads to more frag- 
mentation, because in most cases the $\mathrm{OH}$ attack is now next to other functional moieties (e.g., multifunctional ketones).

Figure 3 shows the effect of gas-phase photolysis on oxygen to carbon $(\mathrm{O} / \mathrm{C})$ ratios of particles for the BASE run. For all cases, changes in $\mathrm{O} / \mathrm{C}$ ratios $(<0.05)$ are minor. Slightly higher $\mathrm{O} / \mathrm{C}$ ratios at low $\mathrm{NO}_{x}$ were found in the presence of gas-phase photolysis as photolyzed fragments are typically smaller and more volatile carbon chains that need to undergo further oxidation to condense into particles. Our results are consistent with chamber studies by Wong et al. (2014) that observed small changes in $\mathrm{O} / \mathrm{C}$ with an increase in more oxidized compounds (high $\mathrm{O} / \mathrm{C}$ ) in $\alpha$-pinene SOA due to fast photodegradation of less oxidized particulate organics such as carbonyls. Changes in SOA composition due to gas-phase photolysis can also affect the volatility distribution of oxidized organic compounds. Figure 4 does not show a clear shift in volatility due to gas-phase photolysis but rather suggests that the SOA reduction is happening across a wide range of volatility bins.

Our explicit modeling results suggest that gas-phase photolysis leads in some cases to moderate changes in SOA yields (<25\% for most precursors; $<45 \%$ for high- $\mathrm{NO}_{x} \alpha$ pinene), and small changes in volatility distribution and $\mathrm{O} / \mathrm{C}$ ratios over 1 equivalent week of chemical aging in the midlatitude atmosphere in summer or 2.5 weeks in winter. The implication in terms of SOA atmospheric lifetime is that gasphase photolysis is a possible sink of intermediate organic vapors and thus SOA, although a smaller sink compared to dry deposition of these gaseous species (Hodzic et al., 2014; Knote et al., 2015). Indeed, the estimated summertime atmospheric lifetimes against photolysis of the SOA from the four precursors considered in our study range from about 10 days for $\alpha$-pinene under high- $\mathrm{NO}_{x}$ conditions (unlikely case) to more than a month for $\alpha$-pinene under low- $\mathrm{NO}_{x}$ conditions or for long-chain $n$-alkane species. These lifetimes are considerably longer than values reported by laboratory studies (e.g., Henry and Donahue, 2012). Current 3-D models typically represent the oxidation products as lumped surrogate species based on their volatility that can further age by $\mathrm{OH}$ oxidation but cannot photolyze due to the undefined chemical structure of those intermediate species. Our results suggest that omitting their gas-phase photolysis will likely result in reasonably small biases in SOA predictions over urban scales. However, errors could be significant at the global scale, in particular in the upper troposphere, where models have the tendency to accumulate SOA due to a less efficient wet removal.

\subsection{Importance of in-particle photolysis of organics}

In the GECKO-A simulations described above, once the organic molecules are partitioned to SOA they are protected from gas-phase photolysis. However, these molecules still contain numerous chromophores (Fig. 2) that absorb solar radiation and could undergo photolysis inside the particle.
Optical absorption is also likely to be modified by the heterogeneous formation of high molecular weight compounds inside the particle (Graber and Rudich, 2006). As GECKOA does not include condensed-phase photochemical reactions (or heterogeneous chemistry), the effect of particlephase photolysis on SOA cannot be calculated directly. In this section, we consider a simple alternative empirical approach to examine the potential effect of particle-phase photolysis within GECKO-A.

We base our estimates of condensed-phase photolysis on the measured SOA mass absorption coefficient (MAC). Organic particles containing photolabile compounds have been shown to efficiently absorb light at actinic wavelengths. Recently measured MAC values range from 0.03 to $0.5 \mathrm{~m}^{2} \mathrm{~g}^{-1}$ for laboratory data (Lambe et al., 2013) or from 0.1 to $10 \mathrm{~m}^{2} \mathrm{~g}^{-1}$ for ambient urban measurements (e.g., Barnard et al., 2008) in the 300-400 nm wavelength interval. We use those measurements to estimate the condensed-phase photolysis of SOA. We represent the photolytic SOA loss as a firstorder reaction, with effective reaction rate coefficient $J_{\mathrm{SOA}}$ :

$J_{\mathrm{SOA}}=[\mathrm{AF}] \times[\mathrm{MAC}] \times[\mathrm{mc}] \times[\mathrm{QY}]$,

where AF is the actinic flux (photons $\mathrm{m}^{-2} \mathrm{~s}^{-1}$ ), MAC is the SOA mass absorption coefficient $\left(\mathrm{m}^{2} \mathrm{~g}^{-1}\right)$, $\mathrm{mc}$ is the mass of one carbon atom $(\mathrm{g})$ and $\mathrm{QY}$ is the quantum yield or the probability that absorbed photons will lead to bond cleavage and the loss of some mass from the particle. We assume that if each absorbed photon leads to the loss of one $\mathrm{C}$ atom, the quantum yield is equal to 1 . We can scale Eq. (1) to known $\mathrm{NO}_{2}$ photolysis:

$J_{\mathrm{SOA}}=J_{\mathrm{NO}_{2}} \times\left[\mathrm{AF} / J_{\mathrm{NO}_{2}}\right] \times[\mathrm{MAC}] \times[\mathrm{mc}] \times[\mathrm{QY}]$

The photolysis model TUV (v5.1; Madronich et al., 1993) was used to estimate the UV actinic flux $\left(=2 \times 10^{20}\right.$ photons $\left.\mathrm{m}^{-2} \mathrm{~s}^{-1}\right)$ and $\mathrm{NO}_{2}$ photolysis $\left(=9.7 \times 10^{-3} \mathrm{~s}^{-1}\right) \quad$ over $\quad 280-400 \mathrm{~nm}$ at $1 \mathrm{~km}$ altitude and overhead sun, which combined with [mc] gives $\left[\mathrm{AF} / J_{\mathrm{NO}_{2}}\right] \times[\mathrm{mc}]=0.4$ photons $\mathrm{g} \mathrm{m}^{-2}$. Thus the resulting SOA photolysis rate can be written as

$J_{\mathrm{SOA}}=0.4 \times J_{\mathrm{NO}_{2}} \times[\mathrm{MAC}] \times[\mathrm{QY}]$.

To estimate the plausible range of $J_{\mathrm{SOA}}$ values, we use the combinations of $[\mathrm{MAC}] \times[\mathrm{QY}]$ reported in the literature. Here we use MAC of $0.1 \mathrm{~m}^{2} \mathrm{~g}^{-1}$ as a lower limit for ambient aerosols. We note that for the chosen MAC value the light can penetrate the whole volume of the particle without being significantly attenuated by the absorbers (light attenuation was estimated to be less than 2-3\%; see discussion in Supplement Annex IV). QY has only been measured for a handful of species. Calvert and Pitts (1966) reported values of 0.01 (or $1 \%$ ) for photolysis of aldehydes in the aqueous phase. Lignell et al. (2013) reported values of 0.5 for $c i s$-pinonic acid, which is one of the constituents of $\alpha$ pinene SOA, whereas Wong et al. (2014) estimated an effective quantum yield of $1.2 \pm 0.2$ for the loss of organics in 

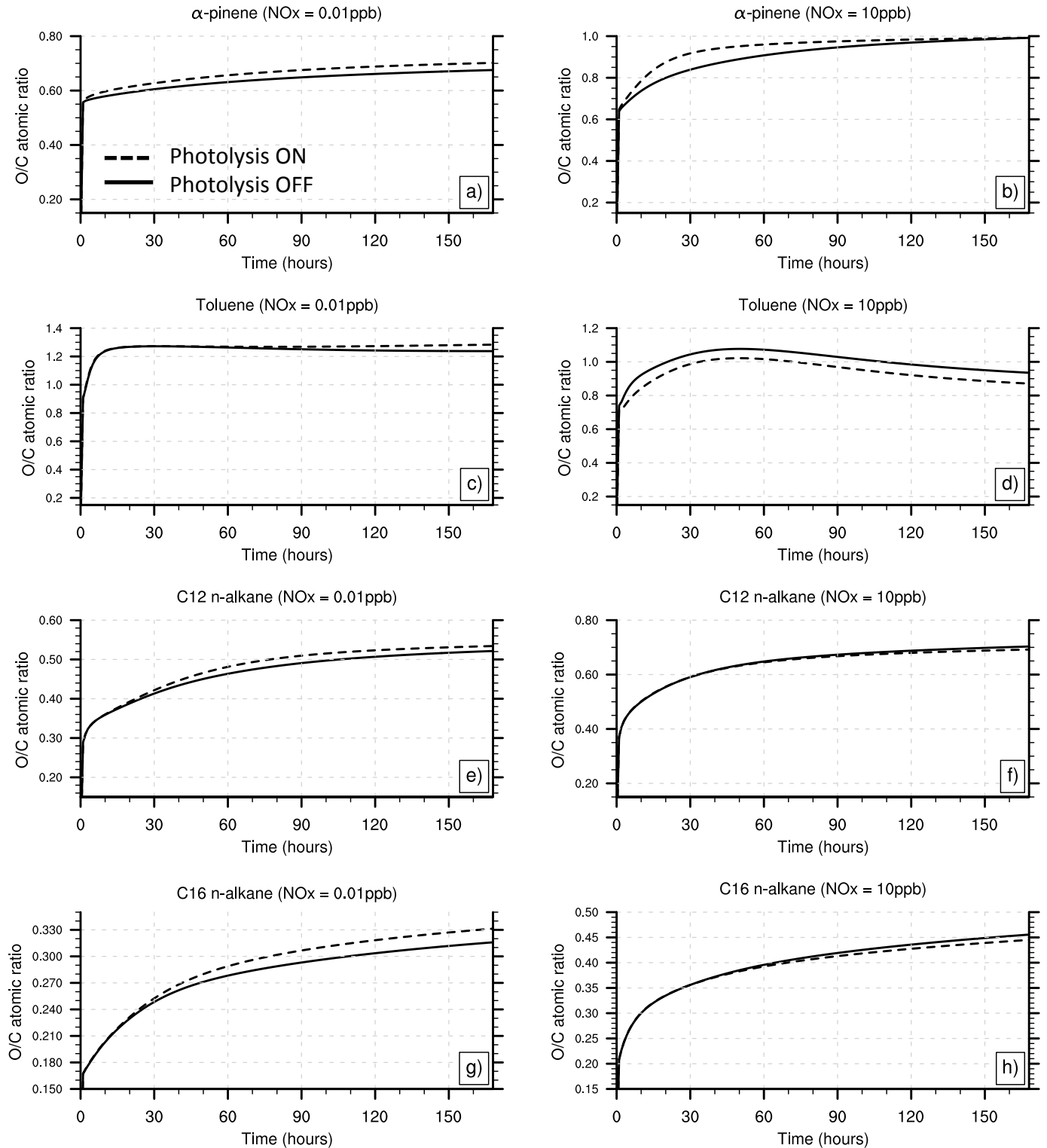

Figure 3. Oxygen to carbon $(\mathrm{O} / \mathrm{C})$ ratios as predicted by the BASE case simulation with (dashed lines) and without (solid lines) gas-phase photolysis of organics.

the case of $\alpha$-pinene SOA photolysis. Given the range of values, here we use a conservative value of 0.01 (or $1 \%$ ) for QY. Thus our best estimate for $J_{\mathrm{SOA}}$ is $0.04 \%$ of $J_{\mathrm{NO}_{2}}$. This value of $J_{\mathrm{SOA}}$ is applied as a first-order removal rate for each photolabile species in the particle phase. The photo-fragments are no longer considered and the condensed-phase photolysis is considered here as an irreversible loss of one carbon atom. We note that this calculated value is $1-2$ orders of magnitude lower that those reported by Henry and Donahue (2012), who estimated the photolytic loss of SOA as $2 \%$ of $J_{\mathrm{NO}_{2}}$ (total value of both particle and gas-phase photolysis and $J_{\mathrm{NO}_{2}}$ of $3 \times 10^{-3} \mathrm{~s}^{-1}$ ). In their experiments, Henry and Donahue (2012) argued that photolysis is more efficient (higher QY) in the gas phase than in the particle phase, where quenching and caging are more likely to occur and could cause rapid recombination of fragments. Therefore a lower QY may be expected in the particles, although it is unclear whether similar molecules are involved in photolysis in the two phases. We also note that photolysis of SOA is assumed to not occur at visible wavelengths (i.e., $Q Y=0$ for $\lambda>400 \mathrm{~nm}$ ).

Figure 5 shows that considering the above estimated condensed-phase photolytic loss of SOA $\left(J_{\mathrm{SOA}}=4 \times 10^{-4} \times J_{\mathrm{NO}_{2}}=3.2 \times 10^{-6} \mathrm{~s}^{-1} ;\right.$ lifetime of 7 days at equivalent $J_{\mathrm{NO}_{2}}$ atmospheric exposure; see Table 1) in GECKO-A simulations leads to a $40-60 \%$ decrease in SOA mass after 10 days of equivalent atmospheric 

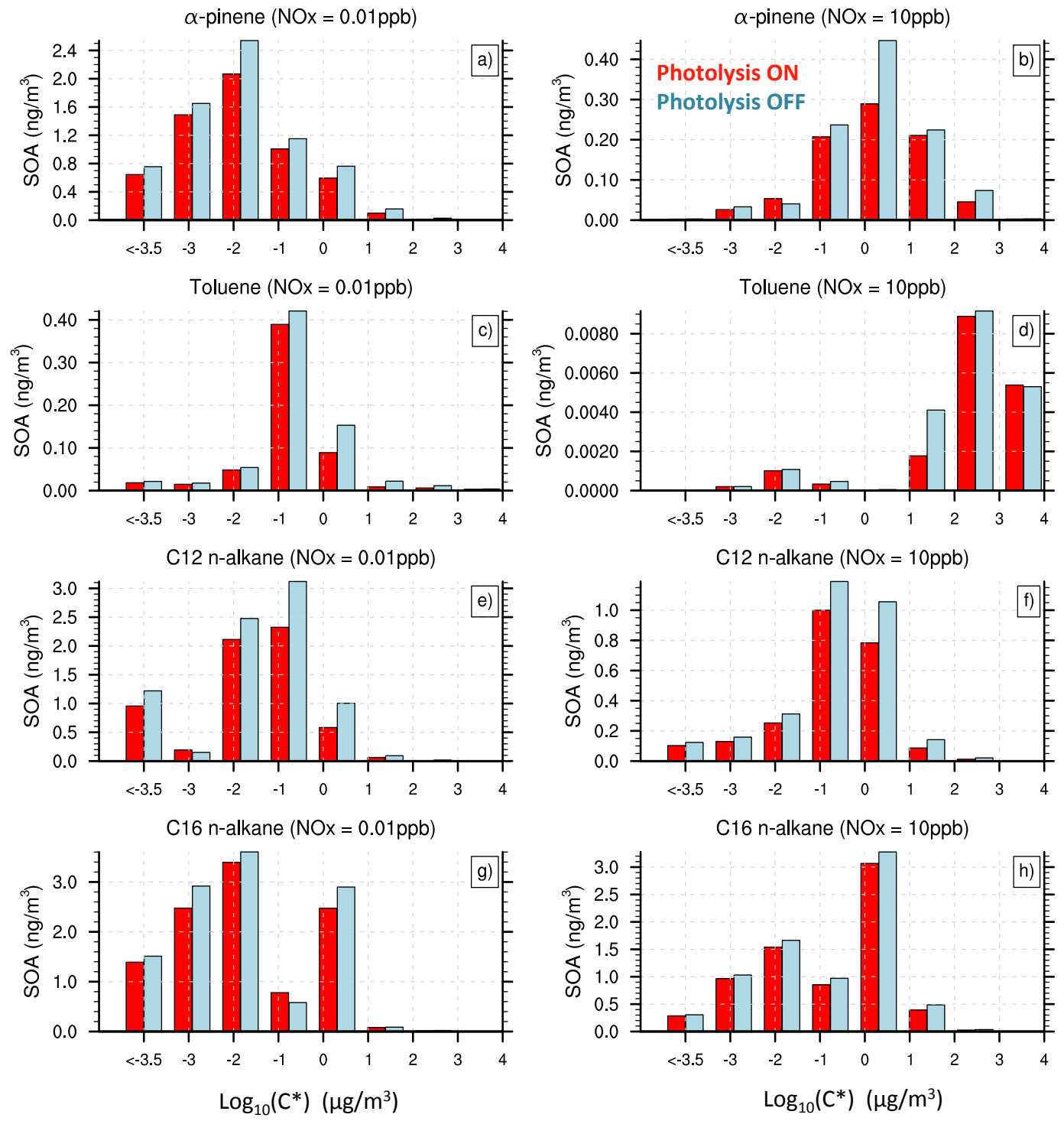

Figure 4. Distribution of products of $\mathrm{OH}$ oxidation of $1 \mathrm{ppt}$ of $\alpha$-pinene, toluene, and $\mathrm{C}_{12}$ and $\mathrm{C}_{16} n$-alkanes at low (0.01 ppb) and high $(10 \mathrm{ppb}) \mathrm{NO}_{x}$ levels according to their volatility. The volatility is expressed in terms of the effective saturation concentration $\left(C^{*}\right)$. Predictions represent values at the maximum SOA yield based on the BASE case simulation with (red) and without (blue) gas-phase photolysis of organics.

aging for most species ( $J_{\operatorname{mac}}$ run, Figs. 5 and $\mathrm{S} 1$ in the Supplement). A more limited decrease $(15 \%)$ is found for the high- $\mathrm{NO}_{x}$ toluene SOA because the photolytic loss of nitroaromatic compounds, which are predicted to be the major SOA constituents (RVVO in Fig. 2), is not included.

For comparison, the effect of applying the gaseous photolysis rates for the corresponding species in the condensed phase is shown in Fig. 5 ( $\left.J_{\text {molecmax }}\right)$. Similar to the simulations above based on MAC, the photolysis here is again considered as an irreversible loss of organic carbon. The comparison between $J_{\text {mac }}$ and $J_{\text {molecmax }}$ shows a fairly similar (within $20 \%$ ) reduction in SOA mass for most precursors. The $J_{\text {molecmax }}$ run considers that chromophores and quantum yields are similar in their gas- and particle-phase absorption, which is a crude assumption neglecting possible effects form oligomerization, caging and quenching. In the absence of particle-phase chemistry, $J_{\text {molecmax }}$ could be viewed as an upper limit to photolysis effects, but changes in absorption with particle aging complicate this simple interpretation as both enhancement and decrease in absorption have been reported (e.g., Shapiro et al., 2009; Bones et al., 2010; Updyke et al., 2012; Zhong and Jang, 2014). In-particle reactions are likely to modify the chemical composition of the particle and therefore change the quantity of photolabile species. For example, the works of Yee et al. (2012) and Schilling-Fahnestock et al. (2014) indicate extensive formation of peroxyhemiac- 

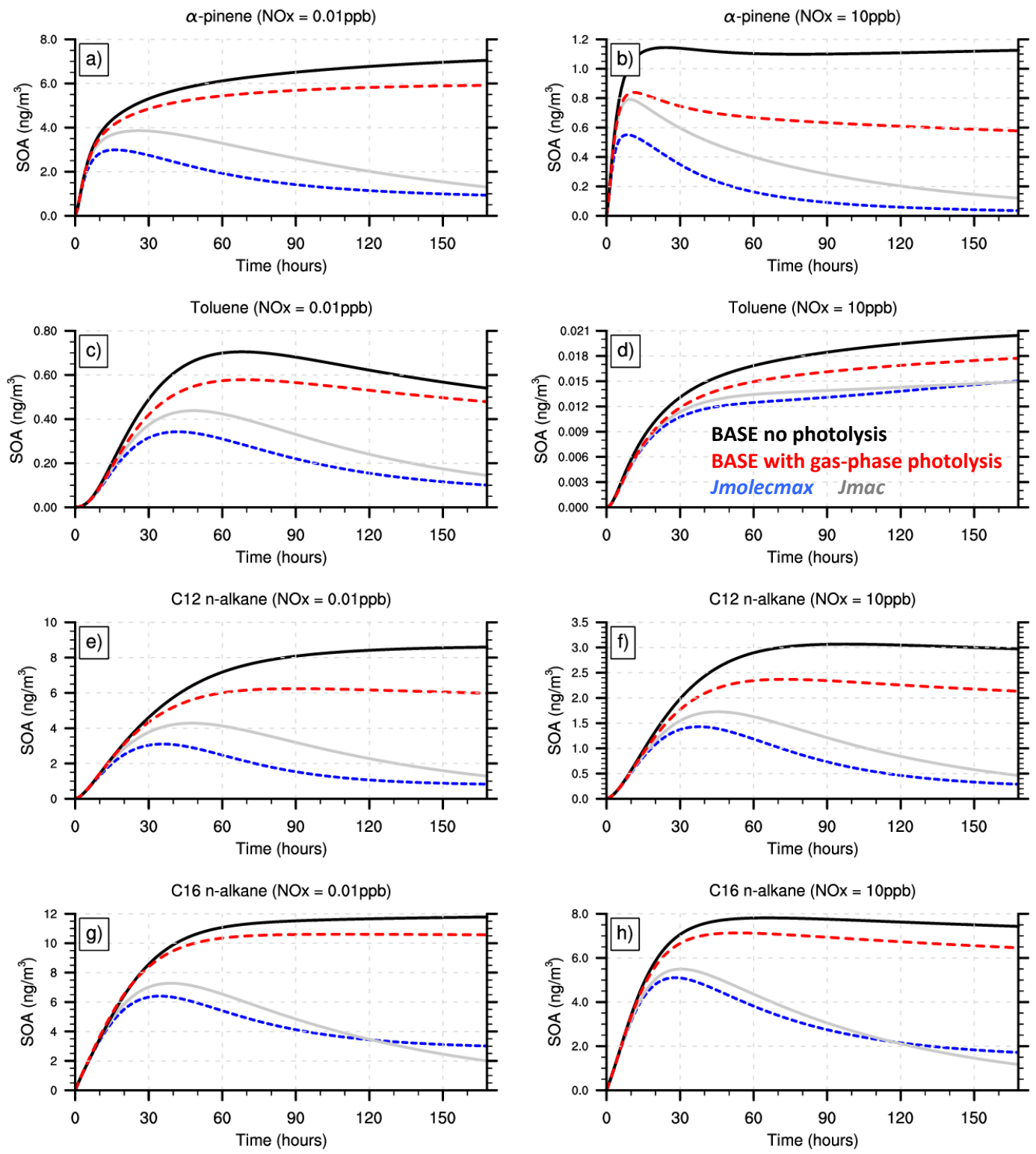

Figure 5. Predicted effect of photolysis on SOA concentrations from the oxidation of $1 \mathrm{ppt}$ of $\alpha$-pinene, toluene, and $\mathrm{C}_{12}$ and $\mathrm{C}_{16} n$-alkanes at low $(0.01 \mathrm{ppb})$ and high $(10 \mathrm{ppb}) \mathrm{NO}_{x}$ levels. Plots compare GECKO-A simulations for the BASE no-photolysis run (black), BASE run with gas-phase photolysis (red), $J_{\text {molecmax }}$ (blue) and $J_{\text {mac }}$ (gray). To derive equivalent atmospheric summertime exposure of our experiments, times should be multiplied by a factor of 2 (Table 1). See Table 2 for the description of various runs.

etals in the SOA from dodecane oxidation at low $\mathrm{NO}_{x}$. However, the precursor molecules are third- and fourth-generation products, which contain additional, unfunctionalized ketone groups, which would still be susceptible to photolysis.

The overall SOA loss rate due to the combined effect of gas- and particle-phase photolysis (and ongoing $\mathrm{OH}$ chemistry) in GECKO-A runs was estimated for the $J_{\mathrm{mac}}$ simulations (see Table 4). Values range between $3.1 \times 10^{-6}$ and $5.6 \times 10^{-6} \mathrm{~s}^{-1}$, which translates to equivalent atmospheric SOA lifetimes of 4 to 8 days with regard to photolysis in the summer, except for high- $\mathrm{NO}_{x}$ toluene $\mathrm{SOA}$ with a lifetime of
20 equivalent summer days, for which the effect of photolysis is likely underestimated in our simulations as discussed above. The estimated SOA lifetime with regard to photolysis is comparable to or even shorter than the typical $\sim 1$-week aerosol atmospheric lifetime, which suggests that photolysis may be an important removal mechanism for atmospheric SOA. Atmospheric implications of our findings are further investigated in Sect. 3.3.

The above estimates for the $\alpha$-pinene SOA photolytic loss rate cannot be directly compared with those of Henry and Donahue (2012) and Wong et al. (2014) due to several fac- 


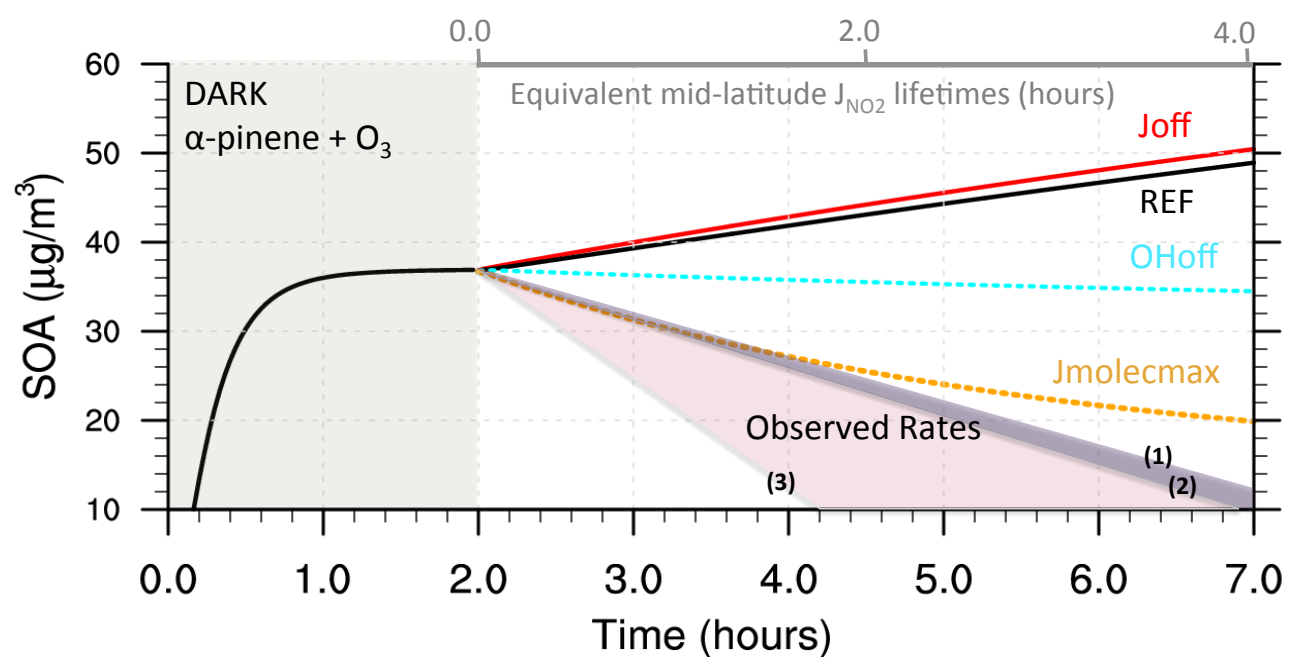

Figure 6. GECKO-A simulation of a typical SOA aging experiment. SOA is first made in the dark in $2 \mathrm{~h}$ from $\alpha$-pinene ozonolysis in the conditions where the formation of hydroperoxides dominates (through $\mathrm{RO}_{2}+\mathrm{HO}_{2}$ reactions). After the second hour the initial precursor has been consumed, and the SOA mixture is exposed to various conditions: (REF, black) UV black lights and $\mathrm{OH}_{\mathrm{H}} \mathrm{of}^{6} \mathrm{molecules} \mathrm{cm}^{-3}$, ( $J_{\text {off }}$, red) only $\mathrm{OH}$ oxidation with $\mathrm{OH}=10^{6}$ molecules $\mathrm{cm}^{-3}$ and photolysis are turned off for organic compounds, $\left(\mathrm{OH}_{\mathrm{off}}, \mathrm{cyan} \mathrm{blue}\right)$ only UV black lights, and ( $J_{\text {molecmax }}$, orange) similar to the REF case but with the photolysis of organic molecules also performed in the condensed phase. The UV lamp is that of Presto et al. (2005), with $J_{\mathrm{NO}_{2}}=3 \times 10^{-3} \mathrm{~s}^{-1}$; during the ageing simulations, $\mathrm{NO}_{x}$ levels are kept at $0.01 \mathrm{ppb}$, ozone levels are set at $50 \mathrm{ppb}$, and $\mathrm{HO}_{2}$ levels are predicted to range between $1.2 \times 10^{8}$ molecules $\mathrm{cm}^{-3}\left(J_{\text {off }}\right)$ and $2 \times 10^{8}$ molecules $\mathrm{cm}^{-3}$ (REF). SOA loss rates reported in the experiments are also shown in shaded purple areas with slopes corresponding to (1) Henry and Donahue (2012) $\left(6 \times 10^{-5} \mathrm{~s}^{-1}\right)$, (2) Wong et al. (2014) for dry conditions $\left(7.9 \times 10^{-5} \mathrm{~s}^{-1}\right)$ and (3) Wong et al. (2014) for humid conditions $\left(1.6 \times 10^{-4} \mathrm{~s}^{-1}\right)$.

Table 4. Estimated loss rates and lifetimes due to gas-phase and in-particle phase photolysis as predicted by GECKO-A for the $J_{\text {mac }}$ simulation over 1 week of aging under constant light $\left(J_{\mathrm{NO}_{2}}=8.1 \times 10^{-3} \mathrm{~s}^{-1}\right)$.

\begin{tabular}{lrr|rr}
\hline $\begin{array}{l}\text { Considered } \\
\text { system }\end{array}$ & \multicolumn{2}{c|}{$\begin{array}{c}\text { Estimated loss } \\
\text { rate }\left(\mathrm{s}^{-1}\right)\end{array}$} & \multicolumn{2}{c}{$\begin{array}{c}\text { Estimated lifetime (days, } \\
\text { under simulation conditions*) }\end{array}$} \\
\hline & Low NO & High NO & Low NO & High $\mathrm{NO}_{x}$ \\
\hline$\alpha$-pinene $+\mathrm{OH}$ & $3.7 \times 10^{-6}$ & $5.6 \times 10^{-6}$ & 3.1 & 2.1 \\
Toluene $+\mathrm{OH}$ & $3.1 \times 10^{-6}$ & $1.1 \times 10^{-6}$ & 3.7 & 10.5 \\
$\mathrm{C}_{12} \mathrm{H}_{26}+\mathrm{OH}$ & $4.7 \times 10^{-6}$ & $4.4 \times 10^{-6}$ & 2.5 & 2.6 \\
$\mathrm{C}_{16} \mathrm{H}_{34}+\mathrm{OH}$ & $3.7 \times 10^{-6}$ & $3.5 \times 10^{-6}$ & 3.1 & 3.3 \\
\hline
\end{tabular}

* To derive equivalent atmospheric loss rates (lifetimes) at mid-latitudes, values should be divided (multiplied) by a factor of 2 in summer and 5.4 in winter, which is the ratio between $J_{\mathrm{NO}_{2}}$ used in our experiment and the typical atmospheric values.

tors: for example, (i) the differences in the chemical composition of particles as the experiments typically use the SOA pre-generated by $\alpha$-pinene ozonolysis for short (a few hours) exposure, whereas in our simulations the SOA is generated mainly by $\mathrm{OH}$ oxidation, and over a much longer time period (> 1 week); (ii) the possible evaporation of SOA in the laboratory experiments due to chamber heating under the UV lamps, which was not quantified in those experiments and which does not occur in our model simulations; and (iii) inparticle chemistry that could modify the composition and absorption properties of the SOA and which is not included in our model, and is generally not well understood.
For comparison with previous laboratory work, we ran the model under conditions similar to Henry and Donahue (2012), in which $\alpha$-pinene was oxidized by ozone in the dark in the presence of hydrogen peroxide, and then the mixture was exposed to UV black lights as in Presto et al. (2005) and/or to $\mathrm{OH}$ oxidation. Figure 6 shows the sensitivity of the aerosol mass to assumed photolysis rates for these conditions. The experiment is performed for $5 \mathrm{~h}$ at the constant $J_{\mathrm{NO}_{2}}$ of $3 \times 10^{-3} \mathrm{~s}^{-1}$, which corresponds to $4 \mathrm{~h}$ of equivalent summertime atmospheric exposure (Table 1). Our results show that when exposed to only $\mathrm{OH}$ reactions (photolysis of organics was turned off), SOA concentrations increase by 

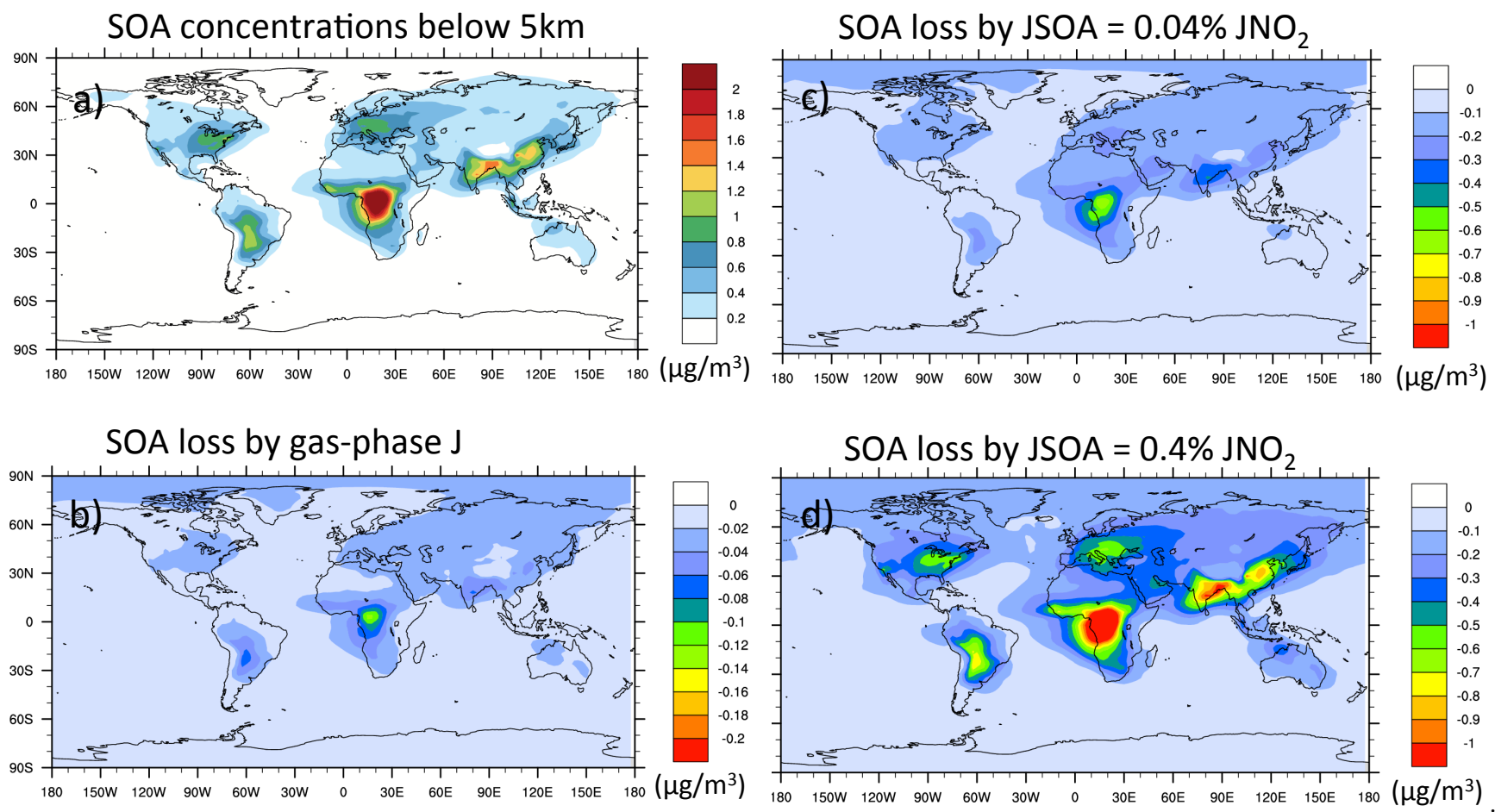

Figure 7. GEOS-Chem simulation for 2009 showing (a) the SOA concentrations within the lower troposphere (below $5 \mathrm{~km}$ ) and the absolute $\left(\mu \mathrm{g} \mathrm{m}^{-3}\right)$ reductions in SOA concentrations due to gas-phase (b) and particle-phase (c, d) photolysis. Gas-phase photolysis is applied to semi-volatile organic compounds using the $e$-folding $J$ lifetime of 20 days as estimated in Table 3 . Two in-particle photolysis rates are considered, i.e., $J_{\mathrm{SOA}}$ of $0.04 \% J_{\mathrm{NO}_{2}}$ (c) and $J_{\mathrm{SOA}}$ of $0.4 \% J_{\mathrm{NO}_{2}}$ (d)

SOA loss by JSOA $=0.04 \% \mathrm{JNO}_{2}$
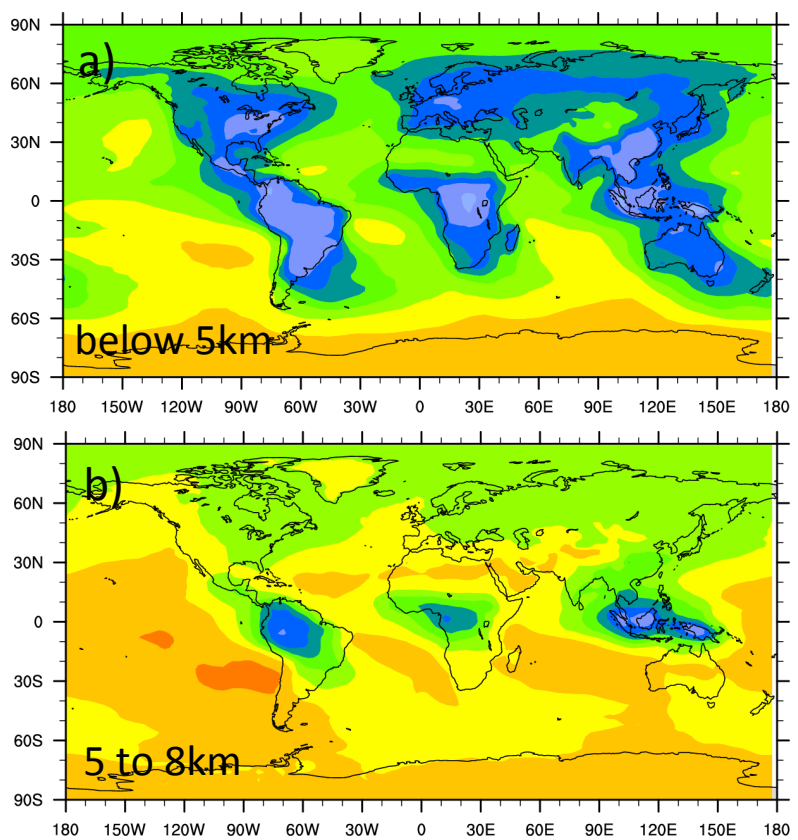

SOA loss by JSOA $=0.4 \% \mathrm{JNO}_{2}$
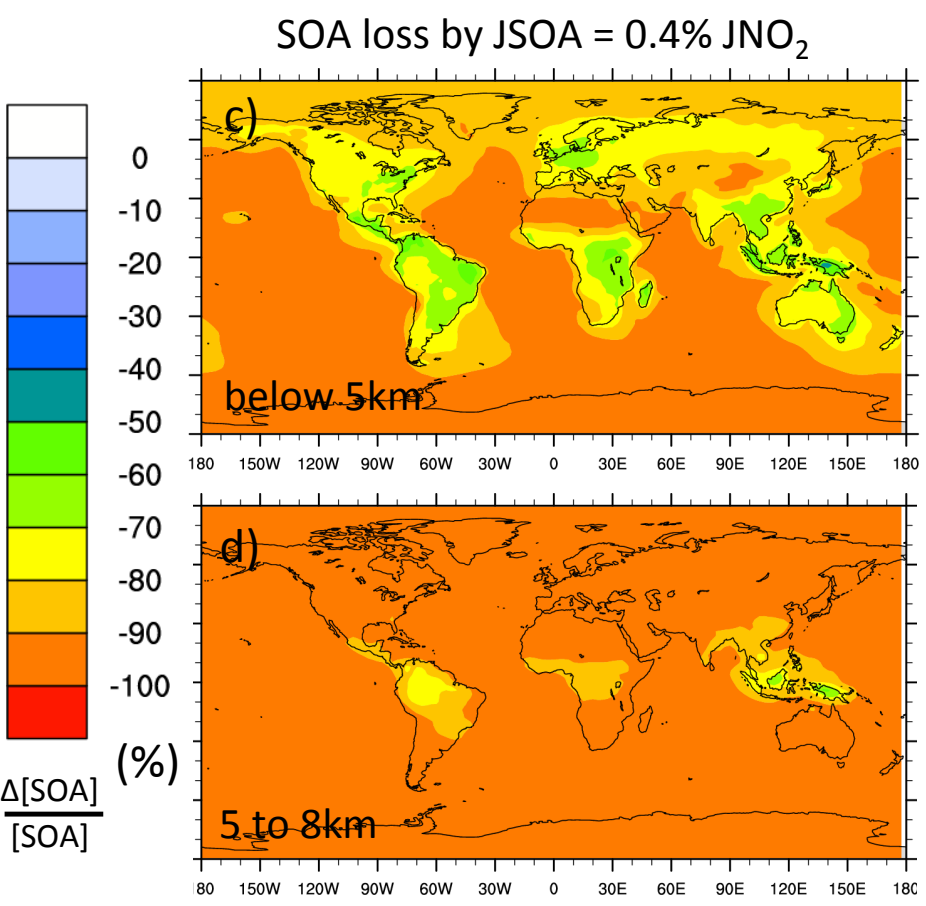

Figure 8. Relative reductions (\%) in SOA concentrations due to particle-phase photolysis in the lower (a, c) and upper (b, d) troposphere. Two in-particle photolysis rates are considered, i.e., $J_{\mathrm{SOA}}$ of $0.04 \% J_{\mathrm{NO}_{2}}$ (left side) and $J_{\mathrm{SOA}}$ of $0.4 \% J_{\mathrm{NO}_{2}}$ (right side). 
$\sim 35 \%$ in $5 \mathrm{~h}$ of aging. On the other hand, SOAs exposed to only photolytic reactions (no $\mathrm{OH}$ ) decrease by $\sim 7 \%$ over the simulation period. The combined effect of both photolytic and $\mathrm{OH}$ reactions is therefore an overall increase in SOA concentrations by $\sim 30 \%$. As done previously, we also performed a sensitivity simulation in which all molecules can photolyze in both gas and particle phases at the gas-phase rate. Figure 6 shows that, with those reactions, the SOA concentrations are decreased by $\sim 50 \%\left(J_{\text {molecmax }}\right)$ in $5 \mathrm{~h}$. These results suggest that most of the photolabile molecules are partitioned to the particle phase, where they are protected from gas-phase photolysis. The corresponding loss rate due to the combined effect of gas- and particle-phase photolysis and $\mathrm{OH}$ oxidation, is $3.4 \times 10^{-5} \mathrm{~s}^{-1}$, which is within a factor of 2-3 of the values reported by Henry and Donahue (2012) and Wong et al. (2014).

\subsection{Potential effect of photolysis on global SOA budget and lifetime}

We implement the estimated SOA gas-phase and in-particle photolytic loss rates within the GEOS-Chem global chemistry model (Bey et al., 2001) to investigate the regional and global effect of photolytic reactions on SOA concentrations. The GEOS-Chem model configuration used in this study is described in detail by Jo et al. (2013). In particular, SOA is modeled using volatility basis set approach with aging in which oxygenated semi-volatile organic compounds (SVOCs) formed by the gas-phase reaction of nine lumped hydrocarbon species (representing monoterpenes, sesquiterpenes, isoprene, and aromatic compounds) with $\mathrm{OH}, \mathrm{O}_{3}$, and $\mathrm{NO}_{3}$ are partitioned between gas and particle phases using six volatility bins (with saturation vapor pressures ranging from 0.01 to $1000 \mu \mathrm{g} \mathrm{m}^{-3}$ at $300 \mathrm{~K}$ ). Chemical aging of anthropogenic SVOCs with $\mathrm{OH}$ (with a rate constant of $4 \times 10^{-11} \mathrm{~cm}^{3}$ molecules ${ }^{-1} \mathrm{~s}^{-1}$ ) is assumed to reduce the vapor pressure of the products by 1 order of magnitude. Model simulations are performed for year 2009.

Figure 7 shows the annual mean SOA concentrations predicted by the default GEOS-Chem run within the lower troposphere (below $5 \mathrm{~km}$ ). The predicted continental background levels of SOA typically vary between 0.2 and $0.4 \mu \mathrm{g} \mathrm{m}^{-3}$, and the highest concentrations $\left(>1.5 \mu \mathrm{g} \mathrm{m}^{-3}\right)$ are found over tropical forest regions of Africa and South America. Industrialized and urban areas in China, Europe and the USA feature SOA values significantly larger (0.5$1.5 \mu \mathrm{g} \mathrm{m}^{-3}$ ) than the background. These SOA values and spatial distribution are consistent with previous studies (e.g., Spracklen et al., 2011; Jo et al., 2013). Our results (Fig. 7b) suggest that gas-phase photolysis of intermediate semivolatile organic compounds leads to a very small $(<4 \%)$ reduction in SOA concentrations under ambient conditions. A much larger impact on SOA concentrations is predicted for in-particle photolysis. When the previously estimated photolytic loss of $0.04 \% J_{\mathrm{NO}_{2}}$ is applied within the GEOS-Chem model, the annual mean SOA concentrations in the lower troposphere are decreased by $\sim 20-30 \%$ over source regions, and up to $60 \%$ over remote regions (Fig. 8a). The absolute decrease is $\sim 0.3 \mu \mathrm{g} \mathrm{m}^{-3}$ over land and $\sim 0.1 \mu \mathrm{g} \mathrm{m}^{-3}$ over oceans, with the highest absolute decrease of $0.6 \mu \mathrm{g} \mathrm{m}^{-3}$ coinciding with the maximum predicted SOA concentrations over Africa (Fig. 7c). As the quantum yield of the particle-phase photolysis and mass absorption coefficients are highly uncertain, here we also consider an order of magnitude higher photolytic loss rate of $0.4 \% J_{\mathrm{NO}_{2}}$. As shown in Fig. 8c, this increase in $J_{\mathrm{SOA}}$ results in a larger reduction of SOA concentrations in the lower troposphere reaching $50-70 \%$ over land surfaces, and up to $70-90 \%$ over water surfaces. In both cases, a strong spatial gradient is found between land and water surfaces, with larger relative reductions in SOA concentrations over oceans. This gradient is due to the continuous photolytic losses, the effect of which accumulates further away from source regions. Model results show that the relative decrease in SOA concentrations is $\sim 20-30 \%$ stronger in the upper troposphere compared to the lower troposphere (Fig. 8b, d).

Our results suggest that photolysis of SOA, which is currently ignored in chemistry-climate and air quality models, could be an efficient removal process for organic particles. The diagnosed SOA tropospheric lifetime against photolytic removal (annual-average tropospheric mass burden divided by the annual tropospheric loss due to photolysis) ranges from 1 day for $J_{\mathrm{SOA}}=0.4 \% J_{\mathrm{NO}_{2}}$ to 7 days for $J_{\mathrm{SOA}}=0.04 \% J_{\mathrm{NO}_{2}}$, and is comparable to the lifetime associated with the SOA wet deposition, which ranges from 3.5 to 5.5 days in these model runs. This photolytic loss pathway is expected to play a particularly important role in regions where wet deposition is not very efficient such as the upper troposphere and lower stratosphere.

\section{Conclusions}

In this study, we investigated the sensitivity of SOA formation and aging in the atmosphere to gas-phase and inparticle photolysis reactions of organic compounds that actively partition between gas and particle phases. We apply the explicit chemistry model GECKO-A to simulate SOA formation from $\mathrm{OH}$ oxidation of $\alpha$-pinene, toluene, and $\mathrm{C}_{12}$ and $\mathrm{C}_{16} n$-alkane precursors, and to explore the sensitivity of this formation to gas-phase photolysis explicitly calculated in the model. Our simulations are conducted for typical mid-latitude conditions (Boulder, $\mathrm{CO}$ ) and a solar zenith angle of $45^{\circ}$ under a week of permanent daylight. The results suggest that photolysis of intermediate organic compounds in the gas phase leads to a moderate decrease in SOA yields, i.e., $\sim 15 \%$ (low $\mathrm{NO}_{x}$ ) to $\sim 45 \%\left(\right.$ high $\mathrm{NO}_{x}$ ) for $\alpha$ pinene, $\sim 15 \%$ for toluene, $\sim 25 \%$ for $\mathrm{C}_{12} n$-alkane, and $\sim 10 \%$ for $\mathrm{C}_{16} n$-alkane during 8 days of equivalent atmospheric exposure in the summer or 3 weeks in winter. This 
decrease depends on the aerosol chemical composition under various $\mathrm{NO}_{x}$ levels, as well as on the quantity of photolabile molecules. SOA formed from precursors considered here contained a substantial quantity of photolabile molecules, many of which were partitioned to the particle phase before they could undergo gas-phase photolysis.

We performed sensitivity studies to estimate the potential effect of condensed-phase photolysis on SOA formation by applying an empirical $J_{\mathrm{SOA}}$ rate of $4 \times 10^{-4} \times J_{\mathrm{NO}_{2}} \mathrm{~s}^{-1}$ to formed particles. Our results suggest that condensed-phase photolysis might have a substantial effect on SOA formation and subsequent aging, with a decrease of $40-60 \%$ in SOA yields over 10 days of equivalent atmospheric aging at midlatitudes in the summer.

Explicit modeling of a typical $\alpha$-pinene ozonolysis SOA aging experiment was also performed using GECKO-A. The results show a minor decrease $(\sim 7 \%)$ in SOA concentrations in $5 \mathrm{~h}$ of the aging experiment due to gas-phase photolysis of organic vapors under black UV lights. The SOA decrease is much more pronounced $(\sim 50 \%)$ during the experiment when particle-phase photolysis was added using the gasphase rates. The corresponding loss rate due to the combined effect of gas- and particle-phase photolysis is $3.4 \times 10^{-5} \mathrm{~s}^{-1}$, which is within a factor of 2-3 of the values reported by Henry and Donahue (2012) and Wong et al. (2014).

These photolysis processes were parameterized in a global chemistry model, and the results suggest that condensedphase photolytic reactions of organic aerosols could be an important loss process in the atmosphere, removing SOA from the troposphere on timescales of $\sim 7$ days, which is comparable to those timescales for wet deposition. In comparison, the gas-phase photolysis of semi-volatile organic compounds had a much smaller effect on SOA concentrations. We recognize that processes occurring inside the particle phase (e.g., oligomerization), which were not included in our study, can modify the chemical composition and properties of those chromophores, thus enhancing or reducing their ability to absorb radiation and undergo photolysis. These reactions are still not well characterized (Atkinson and Ziemann, 2012) and are beyond the scope of this paper.

We note that the absorption by organic gases and/or particles is not expected to substantially affect the radiation field itself. Even in highly polluted conditions, aerosol optical depth (AOD) rarely exceeds 2 , and only a fraction (1 minus the single-scattering albedo (SSA)) is absorbed, for example $\mathrm{AOD}=2$, and SSA $=0.9$ gives an absorption optical depth of 0.2 , corresponding to about $20 \%$ reduction in radiation. This is a significant but not overwhelming reduction, so that even under these highly polluted conditions the photochemistry is expected to proceed vigorously. Regional and global effects are expected to be smaller.

The implications of our results in terms of SOA modeling are twofold: (i) gas-phase photolysis of intermediate organic vapors, which are currently ignored in most models, are likely to have a moderate impact on SOA yields over typ- ical aerosol lifetimes in the atmosphere, and (ii) in-particle photolysis could be a major sink for SOA if the quantum yields are substantial, and these need to be better constrained from measurements and included in 3-D models. It is also worth noting that a substantial sink due to in-particle photolysis would imply that our current estimates of SOA formation rates would have to be revised upwards to be consistent with observed atmospheric SOA burdens. Finally, we note that a fuller understanding of ambient SOA formation rates will require a better understanding of SOA formation from other condensed-phase processes such as oligomerization and aqueous-phase chemistry.

\section{The Supplement related to this article is available online at doi:10.5194/acp-15-9253-2015-supplement.}

Acknowledgements. We thank Andrew Conley (NCAR) for help with mathematical fitting, Albert Presto (CMU) for providing the UV lamp spectrum, and Duseong Jo and Rokjin Park (Seoul National University) for providing the GEOS-Chem model code and for their assistance in developing the photolysis module for the model. This research was supported by the National Center for Atmospheric Research, which is operated by the University Corporation for Atmospheric Research on behalf of the National Science Foundation, and by DOE (BER/ASR) through grant DE-SC0006711. We would like to acknowledge high-performance computing support from Yellowstone provided by NCAR's Computational and Information Systems Laboratory. Any opinions, findings and conclusions or recommendations expressed in the publication are those of the author(s) and do not necessarily reflect the views of the National Science Foundation. J. L. Jimenez was partially supported by DOE (BER/ASR) DE-SC0011105.

Edited by: M. Kanakidou

\section{References}

Aumont, B., Szopa, S., and Madronich, S.: Modelling the evolution of organic carbon during its gas-phase tropospheric oxidation: development of an explicit model based on a self generating approach, Atmos. Chem. Phys., 5, 2497-2517, doi:10.5194/acp-52497-2005, 2005.

Aumont, B., Valorso, R., Mouchel-Vallon, C., Camredon, M., LeeTaylor, J., and Madronich, S.: Modeling SOA formation from the oxidation of intermediate volatility n-alkanes, Atmos. Chem. Phys., 12, 7577-7589, doi:10.5194/acp-12-7577-2012, 2012.

Barnard, J. C., Volkamer, R., and Kassianov, E. I.: Estimation of the mass absorption cross section of the organic carbon component of aerosols in the Mexico City Metropolitan Area, Atmos. Chem. Phys., 8, 6665-6679, doi:10.5194/acp-8-6665-2008, 2008.

Bey, I., Jacob, D. J., Yantosca, R. M., Logan, J. A., Field, B., Fiore, A. M., Li, Q., Liu, H., Mickley, L. J., and Schultz, M.: Global 
modeling of tropospheric chemistry with assimilated meteorology: Model description and evaluation, J. Geophys. Res., 106, 23073-23096, 2001.

Bones, D. L., Henricksen, D. K., Mang, S. A., Gonsior, M., Bateman, A. P., Nguyen, T. B., Cooper, W. J., and Nizkorodov, S. A.: Appearance of strong absorbers and fluorophores in limonene$\mathrm{O}_{3}$ secondary organic aerosol due to $\mathrm{NH}_{4}^{+}$-mediated chemical aging over long time scales, J. Geophys. Res.-Atmos., 115, D05203, doi:10.1029/2009JD012864, 2010.

Boucher, O., Randall, D., Artaxo, P., Bretherton, C., Feingold, G., Forster, P., Kerminen, V.-M., Kondo, Y., Liao, H., Lohmann, U., Rasch, P., Satheesh, S. K., Sherwood, S., Stevens, B., and Zhang, X. Y.: Clouds and Aerosols, in: Climate Change 2013: The Physical Science Basis. Contribution of Working Group I to the Fifth Assessment Report of the Intergovernmental Panel on Climate Chang, edited by: Stocker, T. F., Qin, D., Plattner, G.-K., Tignor, M., Allen, S. K., Boschung, J., Nauels, A., Xia, Y., Bex, V., and Midgley, P. M., Cambridge University Press, Cambridge, United Kingdom and New York, NY, USA, 2013.

Denjean, C., Formenti, P., Picquet-Varrault, B., Camredon, M., Pangui, E., Zapf, P., Katrib, Y., Giorio, C., Tapparo, A., TemimeRoussel, B., Monod, A., Aumont, B., and Doussin, J. F.: Aging of secondary organic aerosol generated from the ozonolysis of a-pinene: effects of ozone, light and temperature, Atmos. Chem. Phys., 15, 883-897, doi:10.5194/acp-15-883-2015, 2015.

Donahue, N. M., Henry, K. M., Mentel, T. F., Kiendler-Scharr, A., Spindler, C., Bohn, B., Brauers, T., Dorn, H. P., Fuchs, H., Tillmann, R., Wahner, A., Saathoff, H., Naumann, K. H., Möhler, O., Leisner, T., Müller, L., Reinnig, M. C., Hoffmann, T., Salo, K., Hallquist, M., Frosch, M., Bilde, M., Tritscher, T., Barmet, P., Praplan, A. P., DeCarlo, P. F., Dommen, J., Prévôt, A. S., and Baltensperger, U.: Aging of biogenic secondary organic aerosol via gas-phase $\mathrm{OH}$ radical reactions, P. Natl. Acad. Sci., 21, 1350313508, doi:10.1073/pnas.1115186109, 2012.

Epstein, S. A., Blair, S. L., and Nizkorodov, S. A.: Direct Photolysis of $\alpha$-Pinene Ozonolysis Secondary Organic Aerosol: Effect on Particle Mass and Peroxide Content, Environ. Sci. Technol., 48, 11251-11258, doi:10.1021/es502350u, 2014.

Fann, N., Lamson, A. D., Anenberg, S. C., Wesson, K., Risley D., and Hubbell, B. J.: Estimating the national public health burden associated with exposure to ambient $\mathrm{PM}_{2.5}$ and ozone, Risk Anal., 32, 81-95, 2012.

Finlayson-Pitts, B. J. and Pitts, J. N.: Chemistry of the upper and lower atmosphere: theory, experiments, and applications, Academic Press, San Diego, 2000.

Graber, E. R. and Rudich, Y.: Atmospheric HULIS: How humic-like are they? A comprehensive and critical review, Atmos. Chem. Phys., 6, 729-753, doi:10.5194/acp-6-729-2006, 2006.

Henry, K. M. and Donahue, N. M.: Photochemical Aging of $\alpha$-Pinene Secondary Organic Aerosol: Effects of $\mathrm{OH}$ Radical Sources and Photolysis, J. Phys. Chem. A, 116, 5932-5940, 2012.

Hodzic, A., Aumont, B., Knote, C., Lee-Taylor, J., Madronich, S., and Tyndall, G.: Volatility dependence of Henry's law constants of condensable organics: Application to estimate depositional loss of secondary organic aerosols, Geophys. Res. Lett., 41, 4795-4804, doi:10.1002/2014GL060649, 2014.

Jenkin, M. E., Saunders, S. M., Wagner, V., and Pilling, M. J.: Protocol for the development of the Master Chemical Mecha- nism, MCM v3 (Part B): tropospheric degradation of aromatic volatile organic compounds, Atmos. Chem. Phys., 3, 181-193, doi:10.5194/acp-3-181-2003, 2003.

Jo, D. S., Park, R. J., Kim, M. J., and Spracklen, D. V.: Effects of chemical aging on global secondary organic aerosol using the volatility basis set approach, Atmos. Environ., 81, 230-244, 2013.

Knote, C., Hodzic, A., and Jimenez, J. L.: The effect of dry and wet deposition of condensable vapors on secondary organic aerosols concentrations over the continental US, Atmos. Chem. Phys., 15, 1-18, doi:10.5194/acp-15-1-2015, 2015.

Kwok, E. S. C. and Atkinson, R.: Estimation of hydroxyl radical reaction rate constants for gas-phase organic compounds using a structure-reactivity relationship: an update, Atmos. Environ., 29, 1685-1695, 1995.

Lambe, E. T., Cappa, C. D., Massoli, P., Onasch, T. B., Forestieri, S. D., Martin, A. T., Cummings, M. J., Croasdale, D. R., Brune, W. H., Worsnop, D. R., and Davidovits, P.: Relationship between oxidation level and optical properties of secondary organic aerosol, Environ. Sci. Technol., 47, 6349-6357, 2013.

Lignell, H., Epstein, S. A., Marvin, M. R., Shemesh, D., Gerber, B., and Nizkorodov, S.: Experimental and theoretical study of aqueous cis-pinonic acid photolysis, J. Phys. Chem. A, 117, 1293012945, 2013.

Madronich, S.: The atmosphere and UV-B radiation at ground level, Environmental UV Photobiology, Plenum Press, 1-39, 1993.

Nannoolal, Y., Rarey, J., and Ramjugernath, D.: Estimation of pure component properties: Part 3. Estimation of the vapor pressure of non-electrolyte organic compounds via group contributions and group interactions, Fluid Phase Equilibr., 269, 117-133, 2008.

Presto, A. A., Huff Hartz, K. E., and Donahue, N. M.: Secondary Organic Aerosol Production from Terpene Ozonolysis 1. Effect of UV Radiation, Environ. Sci. Technol., 39, 7036-7045, 2005.

Salo, K., Hallquist, M., Jonsson, ̊. M., Saathoff, H., Naumann, K.H., Spindler, C., Tillmann, R., Fuchs, H., Bohn, B., Rubach, F., Mentel, Th. F., Müller, L., Reinnig, M., Hoffmann, T., and Donahue, N. M.: Volatility of secondary organic aerosol during $\mathrm{OH}$ radical induced ageing, Atmos. Chem. Phys., 11, 11055-11067, doi:10.5194/acp-11-11055-2011, 2011.

Schilling-Fahnestock, K. A., Yee, L. D., Loza, C. L., Coggon, M. M., Schwantes, R., Zhang, X., Dalleska, N. F., and Seinfeld, J. H.: Secondary Organic Aerosol Composition from $\mathrm{C}_{12}$ Alkanes, J. Phys. Chem. A, 119, 4281-4297, doi:10.1021/jp501779w, 2014.

Shapiro, E. L., Szprengiel, J., Sareen, N., Jen, C. N., Giordano, M. R., and McNeill, V. F.: Light-absorbing secondary organic material formed by glyoxal in aqueous aerosol mimics, Atmos. Chem. Phys., 9, 2289-2300, doi:10.5194/acp-9-2289-2009, 2009.

Spracklen, D. V., Jimenez, J. L., Carslaw, K. S., Worsnop, D. R., Evans, M. J., Mann, G. W., Zhang, Q., Canagaratna, M. R., Allan, J., Coe, H., McFiggans, G., Rap, A., and Forster, P.: Aerosol mass spectrometer constraint on the global secondary organic aerosol budget, Atmos. Chem. Phys., 11, 12109-12136, doi:10.5194/acp-11-12109-2011, 2011.

Tritscher, T., Dommen, J., DeCarlo, P. F., Gysel, M., Barmet, P. B., Praplan, A. P., Weingartner, E., Prévôt, A. S. H., Riipinen, I., Donahue, N. M., and Baltensperger, U.: Volatility and hygroscopicity of aging secondary organic aerosol in a smog cham- 
ber, Atmos. Chem. Phys., 11, 11477-11496, doi:10.5194/acp-1111477-2011, 2011.

Updyke, K. M., Nguyen, T. B., and Nizkorodov, S. A.: Formation of brown carbon via reactions of ammonia with secondary organic aerosols from biogenic and anthropogenic precursors, Atmos. Environ., 63, 22-31, 2012.

Wong, J. P. S, Zhou, S., and Abbatt, P. D.: Changes in Secondary Organic Aerosol Composition and Mass due to Photolysis: Relative Humidity Dependence, J. Phys. Chem. A, 119, 4309-4316, doi:10.1021/jp506898c, 2014.

Yee, L. D., Craven, J. S., Loza, C. L., Schilling, K. A., Ng, N. L., Canagaratna, M. R., Ziemann, P. J., Flagan, R. C., and Seinfeld, J. H.: Secondary organic aerosol formation from low- $\mathrm{NO}_{x}$ photooxidation of dodecane: Evolution of multigeneration gasphase chemistry and aerosol composition, J. Phys. Chem. A, 116, 6211-6230, doi:10.1021/jp211531h, 2012.
Zhang, J., Hartz, K. E. H., Pandis, S. N., and Dohanue, N. M.: Secondary organic aerosol formation from limonene ozonolysis: Homogeneous and heterogeneous influences as a function of $\mathrm{NO}_{x}$, J. Phys. Chem. A, 110, 11053-11063, 2006.

Zhong, M. and Jang, M.: Dynamic light absorption of biomassburning organic carbon photochemically aged under natural sunlight, Atmos. Chem. Phys., 14, 1517-1525, doi:10.5194/acp-141517-2014, 2014.

Ziemann, P. J. and Atkinson, R.: Kinetics, Products, and Mechanism of Secondary Organic Aerosol Formation, Chem. Soc. Rev., 41, 6582-6605, 2012. 